\title{
Multi-Step Loading Creep Behavior of Red Sandstone after Thermal Treatments and a Creep Damage Model
}

\author{
Sheng-Qi Yang ${ }^{1, *}$, Bo Hu ${ }^{1}$ (D), Pathegama G. Ranjith ${ }^{1,2}$ (i) and Peng Xu ${ }^{1}$ \\ 1 State Key Laboratory for Geomechanics and Deep Underground Engineering, School of Mechanics and Civil \\ Engineering, China University of Mining and Technology, Xuzhou 221116, China; \\ hubosk1@hotmail.com (B.H.); ranjith.pg@monash.edu (P.G.R.); blucehu@126.com (P.X.) \\ 2 Deep Earth Energy Research Laboratory, Department of Civil Engineering, Monash University, \\ Melbourne 3800, Australia \\ * Correspondence: yangsqi@hotmail.com; Tel.: +86-516-8399-5856; Fax: +86-516-8399-5678
}

Received: 20 December 2017; Accepted: 10 January 2018; Published: 16 January 2018

\begin{abstract}
Triaxial compressive creep tests were conducted on red sandstones after different thermal treatments. Subsequently, the thermal influence on the axial, lateral and volumetric creep curves under various stress levels was analyzed. The results show that both the instantaneous and time-based deformation behaviors depended largely on the stress and temperature conditions. The instant axial strain increases linearly with increasing deviator stress and the instant deformation modulus decreases non-linearly with temperature. An interesting phenomenon was observed whereby the lateral creep strain had an apparent linear correlation with the axial creep strain. Furthermore, the fitting lines' slopes of lateral and axial creep strain increase gradually with the increasing deviator stress at identical temperature and first decreases and then increases as temperature is elevated. Then, on the basis of the Burgers creep model and the concept of strain energy, a creep damage model implemented in FLAC ${ }^{3 \mathrm{D}}$ (Fast Lagrangian Analysis of Continua 3D) is presented, and this model was able to describe the entire creep process completely including primary creep stage, secondary creep stage, and tertiary creep stage comparing with the experimental and theoretical results based on test data and numerical calculations. The influence of two damage parameters on creep curves and the thermal influence on creep parameters are subsequently discussed. Under the same stress level, the parameters $K, G_{\mathrm{M}}$ and $G_{\mathrm{K}}$ and $\eta_{\mathrm{K}}$ of creep model decrease with temperature, while the parameter $\eta_{\mathrm{M}}$ first augments as temperature rise to $300^{\circ} \mathrm{C}$ and then decreases as temperature at above $300{ }^{\circ} \mathrm{C}$. The higher is the temperature, the smaller the critical stress ratio (CSR).
\end{abstract}

Keywords: red sandstone; thermal effects; multi-step loading; Creep; damage model

\section{Introduction}

The exploration and exploitation of deep resources are not only necessary for the economic and social development for many countries, but also require solutions to basic theoretical problems. Compared with conventional fossil fuels, for instance coal and oil, geothermal energy is one of the most abundant sources of energy, which offers great advantages in cost, reliability and environmental friendliness [1-4]. This has stimulated further investigation on the mechanical behavior of rock at high pressure and temperature. Especially, deep rock masses are subjected to high pressures and temperatures, especially in engineering applications for which the temperature approaches the rock melting point, such as coal gasification underground, where the temperature can exceed $1000{ }^{\circ} \mathrm{C}$ [5-7], volcano flank stability [8-11], and proposals for deep geological burial of high-grade nuclear waste [12-14], and underground coal fires such as the spontaneous combustion of coal seams, where the maximum temperature reaches $1200{ }^{\circ} \mathrm{C}$ [15]. Rock masses involved in projects such as 
post-disaster reconstruction after coal fires and underground coal gasification have experienced high temperature treatments that have a vital influence on their mechanical behavior $[16,17]$.

Therefore, research on underground rock engineering long-term stability is necessary. The influence of temperature on the rheological behavior of rock has been investigated very early [18-20]. Numerous researchers have conducted a variety of creep experiments that primarily considered the influence of different mineral component [21], temperature [10,22], water [23,24], pore water pressure [11,25], and stress [26-28] on the time-dependent behaviors of various rocks. The results show that time-based deformation in brittle rocks is not distinguishable from that in soft rock $[11,29,30]$ and that creep rupture occurs suddenly and over very short times. Commonly, creep deformation presents three stages: transient creep with decreasing strain rate, followed by steady creep at a constant strain rate, and finally tertiary creep with sudden increases in strain rate to rupture [31]. To understand the thermal influence on the creep behaviors of rocks, Chopra [32] investigated the transient creep behaviors of two natural dunite specimens at temperatures between 1373 and $1573 \mathrm{~K}$. Ferrero [33] heated marbles at a ratio of $2.4^{\circ} \mathrm{C} / \mathrm{min}$ to target temperatures and then cooled them at a ratio of $0.23{ }^{\circ} \mathrm{C} / \mathrm{min}$ to induce micro-cracking, and then studied their mechanical behaviors. Du et al. [34] studied the mechanical properties, including stress-strain curve, peak stress and strain, elastic modulus and Poisson's ratio of granite after subjected high temperatures. Heap et al. [10] reported the results of the thermal effects on both short-term strength and time-dependent brittle creep in three sandstones under tri-axial stress conditions. Brotóns et al. [35] investigated the influence of temperature and cooling method (air cooling and water cooling) on the physical and mechanical properties of San Julian' stone. Tian et al. [36,37] summarized in a review the literature on the physical and mechanical properties of sandstones after high-temperature treatment. Tian et al. [38] investigated the physical and mechanical behaviors of claystone exposed to $1000{ }^{\circ} \mathrm{C}$. Li et al. [39] studied the dynamic properties of sandstones with different strain rate after $800^{\circ} \mathrm{C}$. Ye et al. [40] conducted triaxial compression and creep tests on green tuff over temperatures ranging from 20 to $80{ }^{\circ} \mathrm{C}$ and found that peak strength and creep failure time were sensitive to temperature. Sun et al., [41] reported the variations of thermal conductivity, thermal diffusivity and heat capacity of sandstone after high temperature treatment. Yang et al. [1] evaluated the thermal damage and failure mechanical behavior of granite at elevated temperatures, which demonstrated that the crack damage threshold, the strength and static elastic modulus of granite were increased at $300^{\circ} \mathrm{C}$, before decreasing up to the maximum temperature of $800^{\circ} \mathrm{C}$. Yang et al. [2] investigated the triaxial mechanical and permeability behavior of sandstone after exposure to different high temperature treatments.

In addition, proper constitutive models for time-related behaviors of rocks have been abundantly researched. In general, those models can be divided into three distinct methods: (1) empirical models [42,43]; (2) component models [44-46]; and (3) models based on inner mechanisms such as endochronic theory $[47,48]$, thermodynamics $[49,50]$ and damage and fracture mechanics [51-53]. The damage concept was first introduced by Kachanov [54] and elaborated by Lemaitre [55]. The damage model of Kachanov is classified as isotropic damage. The damage model of Kachanov is extended to anisotropic damage by Murakami [56] and this concept was applied to rock mass by Kyoya [57] and it is called damage tensor. Previous research has shown that damage reflected by, for example, porosity changes, cumulative acoustic emission energy and microscopic crack observations during creep processes, occurs in time-dependent rock deformation $[10,11,27,58,59]$. Furthermore, the damage mechanisms include mainly stress corrosion, the initiation $[60,61]$, propagation and coalescence of microcracks, and energy dissipation [62,63]. However, little has been reported on simple and effective creep models for characterizing trimodal creep behavior.

To better understand the influence of temperature on the creep behavior of brittle rocks, this paper presents the results of triaxial compressive creep tests on red sandstones under confining pressures $\left(\sigma_{3}\right)$ of $25 \mathrm{MPa}$ after thermal treatments $\left(25,300,700\right.$ and $\left.1000^{\circ} \mathrm{C}\right)$ and a detailed analysis and discussion of the results. Simultaneously, it is necessary to develop an appropriate and simple creep damage model to characterize the time-based deformation and damage characteristics to better understand the 
creep mechanisms of brittle rock. Finally, a simple creep damage model is proposed considering strain energy and based on a Burgers model.

\section{Experiments}

\subsection{Specimen Preparation}

The red sandstones were obtained from Rizhao (Shandong Province, China). Specimens were cut and polished to form cylinders with diameters of $50 \mathrm{~mm}$ and height-to-width ratios of 2:1. They were then dried for approximately $24 \mathrm{~h}$ at a temperature of $105^{\circ} \mathrm{C}$ in a drying box (SGM High temperature Electric Furnace Limited Company, Shanghai, China). Finally, the specimens were heated to $300{ }^{\circ} \mathrm{C}$, $700{ }^{\circ} \mathrm{C}$ and $1000{ }^{\circ} \mathrm{C}$ in a furnace (SGM High temperature Electric Furnace Limited Company, Shanghai, China) at a rate of $5{ }^{\circ} \mathrm{C} / \mathrm{min}$, after which the temperatures were maintained for $2 \mathrm{~h}$ before being allowed to cool to room temperature. The basic parameters of the tested samples are listed in Table 1.

Table 1. Strength parameters of tested samples.

\begin{tabular}{ccccccc}
\hline $\boldsymbol{T} /{ }^{\circ} \mathbf{C}$ & $\sigma_{3} / \mathbf{M P a}$ & $\sigma_{\mathbf{S}} / \mathbf{M P a}$ & $\sigma_{\mathbf{p}} / \mathbf{M P a}$ & $\sigma_{\mathbf{c d}} / \mathbf{M P a}$ & $E_{\mathbf{S}} / \mathbf{G P a}$ & $E_{50} / \mathbf{G P a}$ \\
\hline 25 & 25 & 259.32 & 234.32 & 223.34 & 26.13 & 28.65 \\
300 & 25 & 269.78 & 244.78 & 228.32 & 28.42 & 28.77 \\
700 & 25 & 316.29 & 291.29 & 263.53 & 25.49 & 21.23 \\
1000 & 25 & 232.36 & 207.36 & 132.99 & 10.49 & 7.84 \\
\hline
\end{tabular}

Note: $\sigma_{\mathrm{S}}=\sigma_{\mathrm{p}}+\sigma_{3} ; \sigma_{\mathrm{p}}$ : the peak strength; $\sigma_{\mathrm{cd}}$ : the crack damage stress; $E_{\mathrm{S}}$ : the elastic modulus (the even slope of the approximately straight line portion); $E_{50}$ : the secant modulus (the slope between the start point and the stress at a half of peak strength).

\subsection{Testing Apparatus and Method}

Rock triaxial rheological testing equipment (TOP INDUSTRIE, Grand Paris, France), whose allowed maximum values of deviatoric stress, confining pressure and pore pressure with water were 400, 70 and $40 \mathrm{MPa}$, respectively, was used to perform creep experiments. In an effort to overcome the influence of specimen differences, a stress stepping methodology was adopted for a single specimen; until the specimen eventually ruptured [27]. Hence, the specimens were first subjected to hydrostatic pressures of $25 \mathrm{MPa}$ and deviatoric stresses were applied to $160 \mathrm{MPa}$ (the first stress level was slightly greater than the lowest $\sigma_{\mathrm{cd}}$ ) under pressure-controlled conditions of $5 \mathrm{MPa} / \mathrm{min}$. They subsequently deformed for approximately 4 days under static compressive stress, after which the deviatoric stress was applied at next level. The above procedures were repeated until failure occurred. The loading procedure is shown in Figure 1.

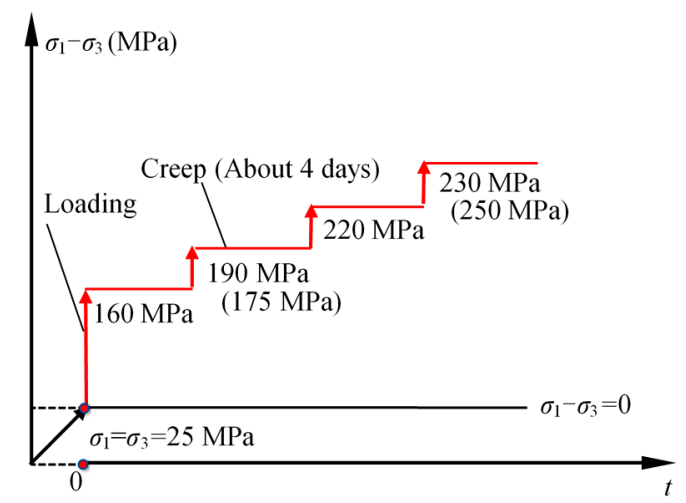

Figure 1. Loading procedure for creep tests. 


\section{Creep Experimental Results}

\subsection{Axial Strain}

The instantaneous deformation under $\sigma_{3}$ of $25 \mathrm{MPa}$ will be analyzed first. Figure 2a illustrates the relationships between instantaneous axial strain $\left(\varepsilon_{0}\right)$ and differential stress under different temperatures. It can be seen that the instantaneous axial strain increased linearly with increasing partial stress under the same temperatures. Moreover, the strain increments also increased gradually as the loadings increased. Approximately monotonic linear correlations between the instantaneous axial strain and deviatoric stresses were found in each thermal-treated specimen.

In particular, the fit line slopes represent the instantaneous deformation modulus $\left(E_{0}\right)$, which decreased with temperature, although the square of the correlation coefficient $\left(R^{2}\right)$ of the specimens at $1000{ }^{\circ} \mathrm{C}$ was not very high. It can be observed that the decrease in $E_{0}$ with increasing temperature was non-linear. Its nonlinear correlation (for the average values at each temperature) can be fitted by the equation shown in Figure $2 b$.
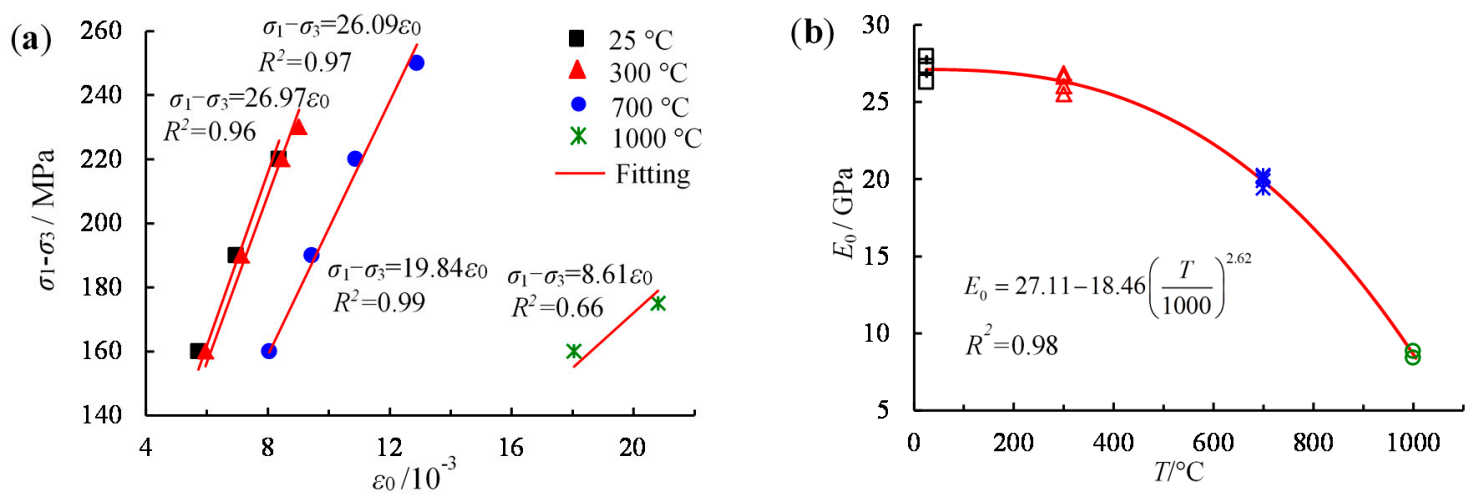

Figure 2. (a) Relation between the axial instantaneous strain and deviator stress and (b) Relation between the instant deformation modulus and temperature.

The axial creep deformations of the specimens at different temperatures were analyzed. Figure 3 shows the variations in the axial creep strains over time for the red sandstones at temperatures of $25,300,700$ and $1000{ }^{\circ} \mathrm{C}$ under $\sigma_{3}$ of $25 \mathrm{MPa}$, respectively. The axial creep strains were positive, which represented axial compression. Figure 3 remarkably indicates that the axial creep strains increased over time under static loading.

As the deviatoric stresses increased, the increments in the axial creep strains rose gradually over time. Under the last loading, the durations of tertiary creep for the specimens at 25, 300, 700 and $1000{ }^{\circ} \mathrm{C}$ were approximately $35.3 \mathrm{~min}, 56.7 \mathrm{~h}, 2.7 \mathrm{~min}$ and $1.9 \mathrm{~h}$, respectively. Commonly, brittle failure over short times at the onset of the accelerated creep stage occurred rapidly. An interesting phenomenon can be observed in Figure $3 \mathrm{~d}$ for the specimen at $1000{ }^{\circ} \mathrm{C}$ and under a deviatoric stress of $175 \mathrm{MPa}$. Primary and steady state creep existed for approximately $0.6 \mathrm{~h}$ after the last stress was applied, after which tertiary creep seems to have occurred, whereas it again showed primary and secondary creep and brittle creep failure in the final accelerating creep stage. The relationship between deviatoric stress and axial creep strain at different temperatures was shown in Figure 3e, in which axial creep increased as deviatoric stress and temperature increased. Figure 4 presents the axial creep strains with creep time at various temperatures under the conditions of deviatoric stresses of 160, 190 and $220 \mathrm{MPa}$, respectively. As shown in Figure 4a, when the deviatoric stress was raised to $160 \mathrm{MPa}$, the axial creep strains and the durations of the primary creep stage increased with increasing temperature. The stress levels were $68 \%, 65 \%, 55 \%$ and $77 \%$ of each $\sigma_{\mathrm{p}}$ at $25,300,700$ and $1000{ }^{\circ} \mathrm{C}$, respectively. However, under deviatoric stresses of $190 \mathrm{MPa}$, the stress level were $81 \%, 78 \%$ and $65 \%$ of each $\sigma_{\mathrm{p}}$ at the four temperatures, and the duration of primary creep for the specimen at $300{ }^{\circ} \mathrm{C}$ was shorter than 
that at room temperature, as shown in Figure $4 \mathrm{~b}$. As shown in Figure $4 \mathrm{c}$, when the deviatoric stress reached to $220 \mathrm{MPa}$, the stress level were $94 \%, 90 \%$ and $76 \%$ of each $\sigma_{\mathrm{p}}$ at $25^{\circ} \mathrm{C}, 300^{\circ} \mathrm{C}$ and $700{ }^{\circ} \mathrm{C}$, respectively, and the specimen at $25^{\circ} \mathrm{C}$ failed quickly, whereas the others experienced steady state creep for approximately $22.7 \mathrm{~h}$ and $28 \mathrm{~h}$.
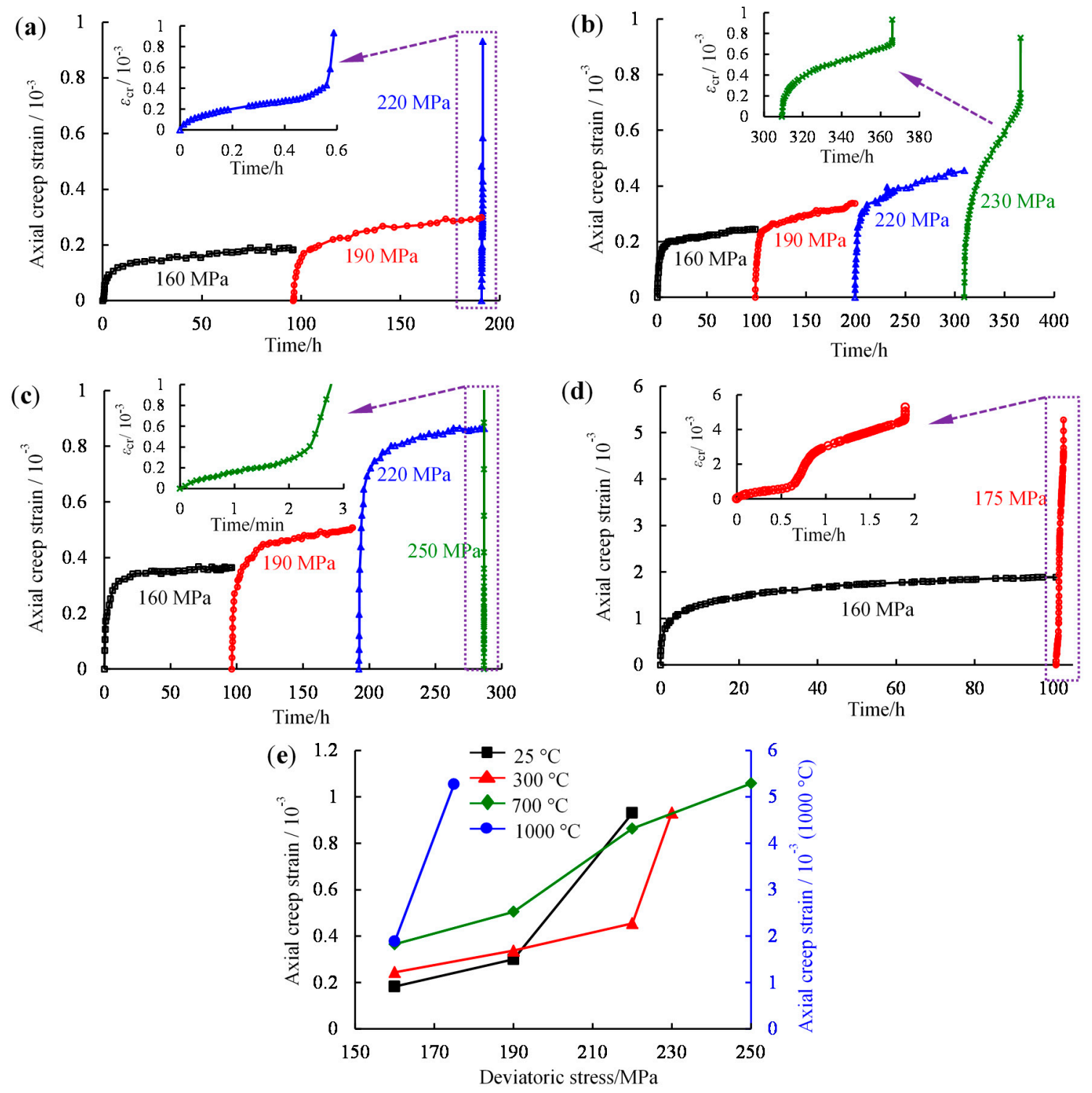

Figure 3. Axial creep strain-time curves under step-loading with $\sigma_{3}$ of $25 \mathrm{MPa}$ at different temperatures: (a) $25{ }^{\circ} \mathrm{C}$; (b) $300{ }^{\circ} \mathrm{C}$; (c) $700{ }^{\circ} \mathrm{C}$; (d) $1000{ }^{\circ} \mathrm{C}$; (e) Relationship between axial creep strain and deviatoric stress.

Figure $4 \mathrm{~d}$ illustrates the relationship between axial creep strain and temperature at identical stress level. When deviatoric stress reached 160 and $190 \mathrm{MPa}$, axial creep strain increased with increasing temperature. Upon combining Figures 3 and 4, it can be found that creep strain depended heavily on applied differential stress and temperature. 

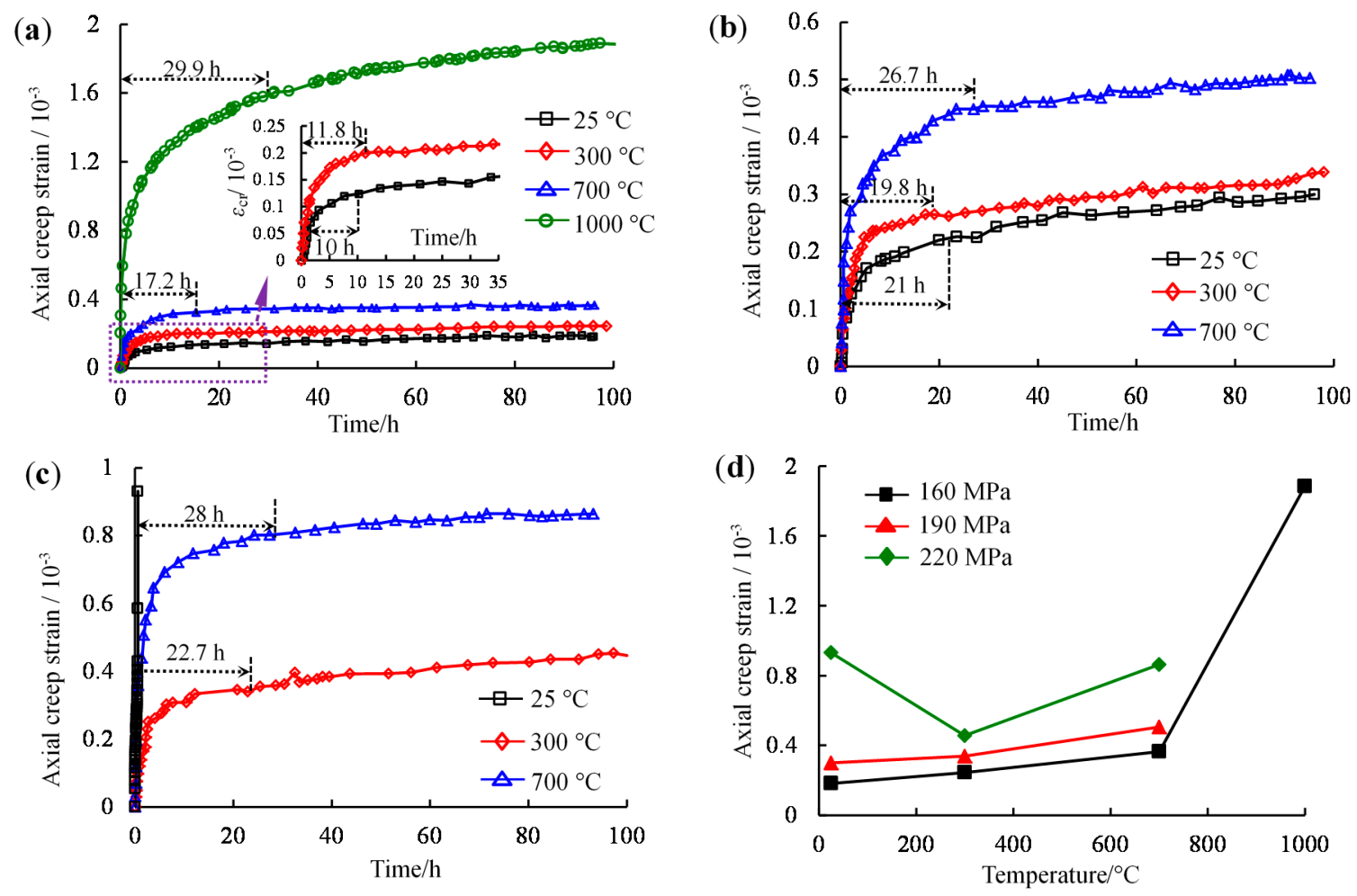

Figure 4. Axial creep strain-time curves under identical stress level at different temperatures $\left(\sigma_{3}=25 \mathrm{MPa}\right):(\mathbf{a}) \sigma_{1}-\sigma_{3}=160 \mathrm{MPa}$; (b) $\sigma_{1}-\sigma_{3}=190 \mathrm{MPa}$; (c) $\sigma_{1}-\sigma_{3}=220 \mathrm{MPa}$; (d) Relationship between axial creep strain and temperature.

\subsection{Lateral Creep Strain}

Lateral deformations can reflect the influence of stress on the lateral expansion of materials. This section will investigate lateral creep strain under increasing deviatoric stress at identical temperatures and under same stresses at various temperatures. It can be seen in Figure 5 that the lateral creep strains commonly were negative, indicating lateral dilatancy. The trimodal creep behavior corresponded to the axial behavior. Lateral creep strain increased with decreasing rate over time for deviatoric stress values below $\sigma_{\mathrm{c}}$. It rose as the partial stress increased. In particular, the creep strain increased rapidly when the loadings reached 220, 230, 250 and $175 \mathrm{MPa}$ for the specimens at 25, 300, 700 and $1000{ }^{\circ} \mathrm{C}$, respectively. That phenomenon indicates that material experienced brittle failure with rapid lateral expansion. Moreover, the relationship between lateral creep strain and deviatoric stress at different temperatures was plotted in Figure $5 \mathrm{e}$.

The lateral creep strains of the specimens at different temperatures under partial stresses of 160 , 190 and $220 \mathrm{MPa}$, respectively, are shown in Figure 6. In Figure 6a, it is obvious that the lateral material dilatancy at $1000{ }^{\circ} \mathrm{C}$ exceeded those of the others by in excess of an order of magnitude. Furthermore, as the temperatures increased from room temperature to $300^{\circ} \mathrm{C}$ the lateral creep strains decreased remarkably but increased when the temperature increased to $700{ }^{\circ} \mathrm{C}$. Similarly, the lateral creep strains first decreased and then increased slightly before and after $300^{\circ} \mathrm{C}$ under a static stress of $190 \mathrm{MPa}$, as shown in Figure 6b. From Figure $6 \mathrm{c}$, when the loading reached $220 \mathrm{MPa}$, the failure and lateral expansion of the specimens at room temperature were rapid. According to the relationship between lateral creep strain and temperature, as shown in Figure 6d, it can be concluded that the lateral creep strains first decreased at temperatures below $300^{\circ} \mathrm{C}$ and then increased when the temperatures rose above $300^{\circ} \mathrm{C}$. 
(a)

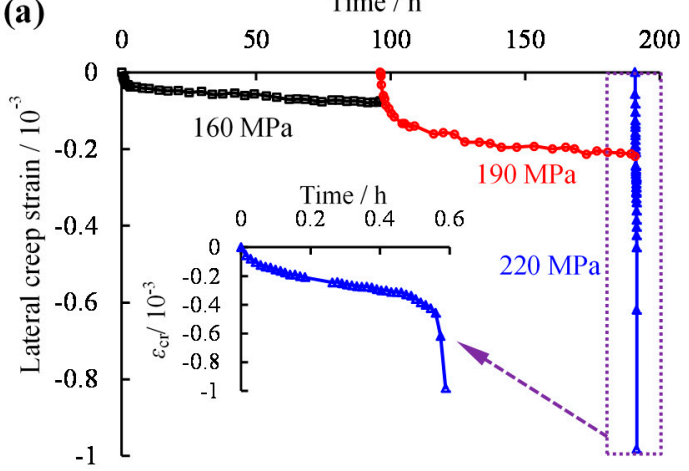

(c)

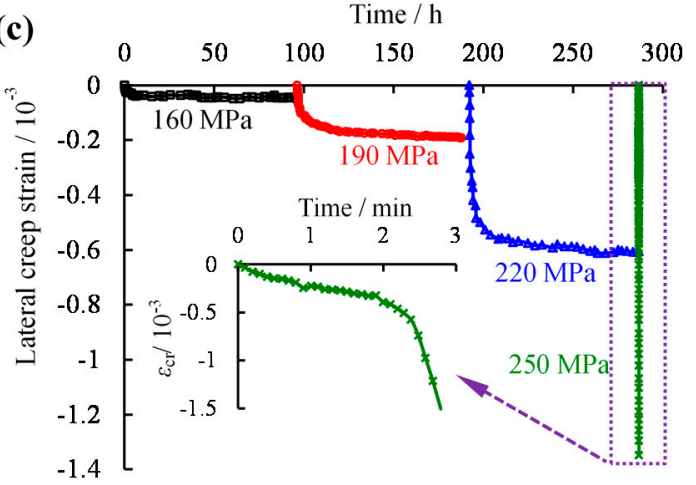

(b)

Time / h

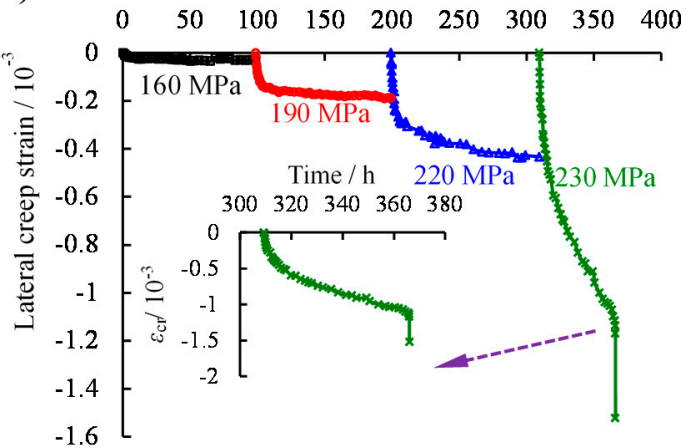

Time / h

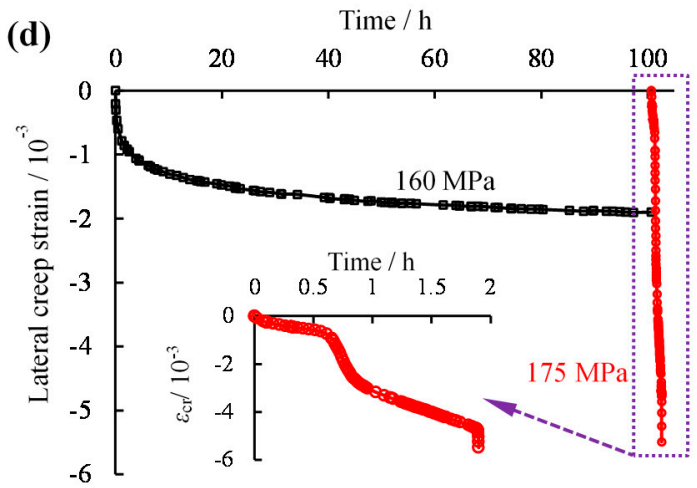

(e) Deviatoric stress / $\mathrm{MPa}$

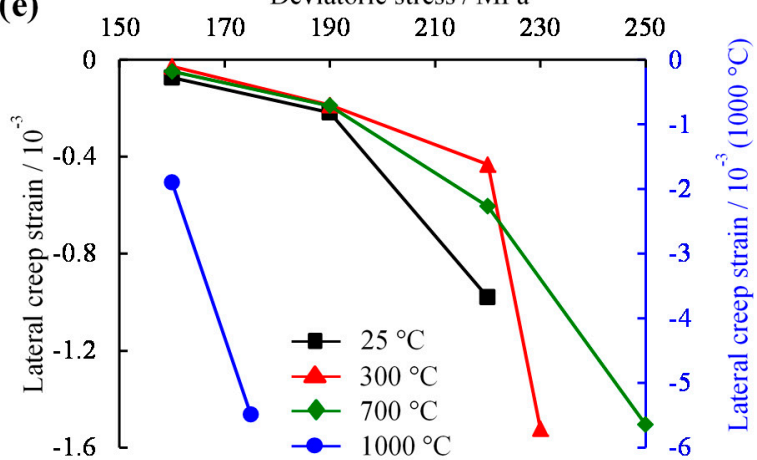

Figure 5. Lateral creep strain-time curves under step-loading at different temperatures $\left(\sigma_{3}=25 \mathrm{MPa}\right)$ : (a) $25{ }^{\circ} \mathrm{C}$; (b) $300{ }^{\circ} \mathrm{C}$; (c) $700{ }^{\circ} \mathrm{C}$; (d) $1000{ }^{\circ} \mathrm{C}$; (e) Relationship between lateral creep strain and deviatoric stress.

(a)

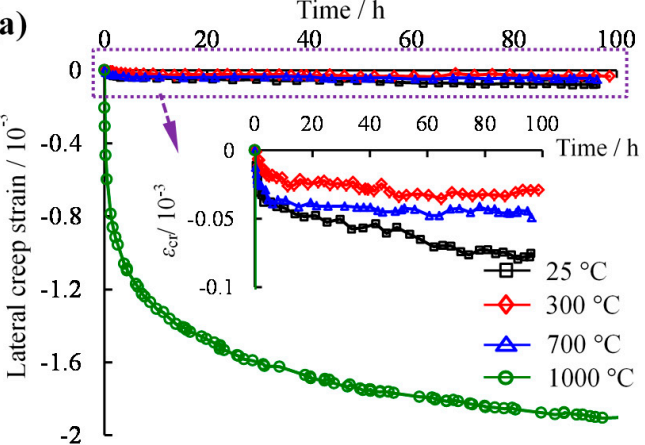

(b) $\quad \begin{array}{llllll} & 0 & \text { Time } / \mathrm{h} & 60 & 80 & 100\end{array}$

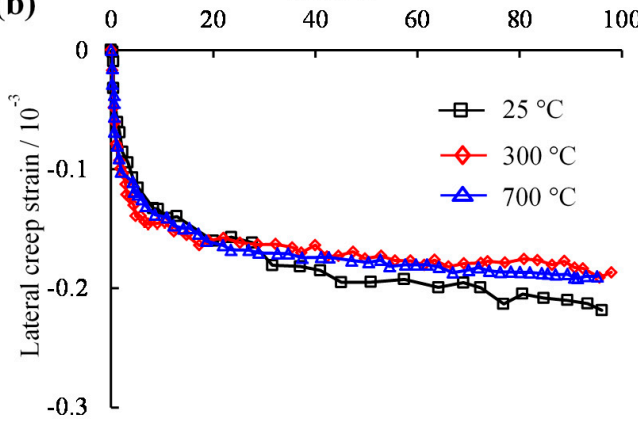

Figure 6. Cont. 

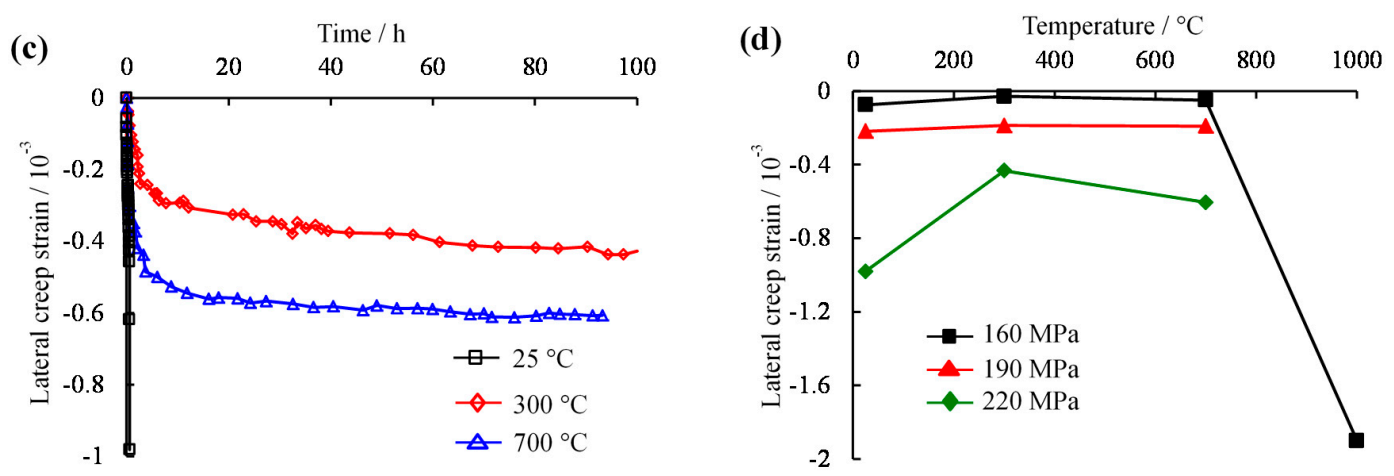

Figure 6. Lateral creep strain-time curves under same stress condition at different temperatures $\left(\sigma_{3}=25 \mathrm{MPa}\right):(\mathbf{a}) \sigma_{1}-\sigma_{3}=160 \mathrm{MPa}$; (b) $\sigma_{1}-\sigma_{3}=190 \mathrm{MPa}$; (c) $\sigma_{1}-\sigma_{3}=220 \mathrm{MPa}$; (d) Relationship between lateral creep and temperature.

\subsection{Volumetric Creep Strain}

Figure 7 shows the relationships of volumetric creep strain and time under increased loading for the specimens at different temperatures. From Figure $7 \mathrm{a}$, the volumetric creep strain was positive under a deviatoric stress of $160 \mathrm{MPa}$, whereas it became negative when the loading exceeded $190 \mathrm{MPa}$ for the specimen at $25^{\circ} \mathrm{C}$. Analogously, the specimen at $300{ }^{\circ} \mathrm{C}$ also shows this characteristic in Figure $7 \mathrm{~b}$. As the temperatures were elevated to $700{ }^{\circ} \mathrm{C}$, the volumetric creeps were positive and decreased as the deviatoric stresses increased from 160 to $190 \mathrm{MPa}$. They subsequently became negative and, in reverse, increased under the loadings exceeding $190 \mathrm{MPa}$. In particular, for the specimens at the highest temperatures, the volumetric creep strains were always negative under the deviatoric stresses of 160 and $175 \mathrm{MPa}$. According to the relationship between volumetric creep strain and deviatoric stress, as shown in Figure 7e, in which lateral expansion increased with increasing differential stress and temperature, as the stress levels gradually increased the specimens at first compressed and then dilated and eventually failed by shear dilatancy.
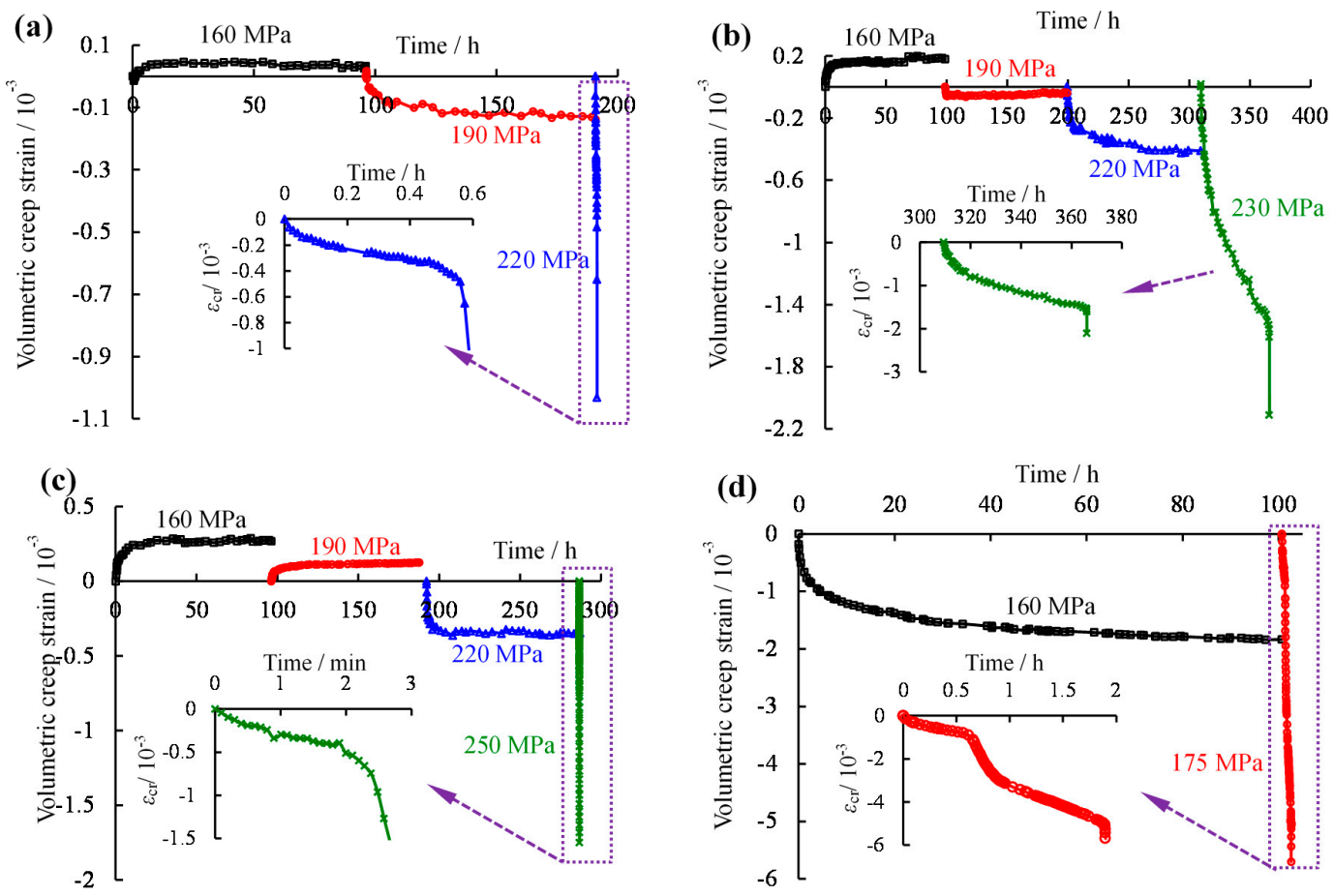

Figure 7. Cont. 


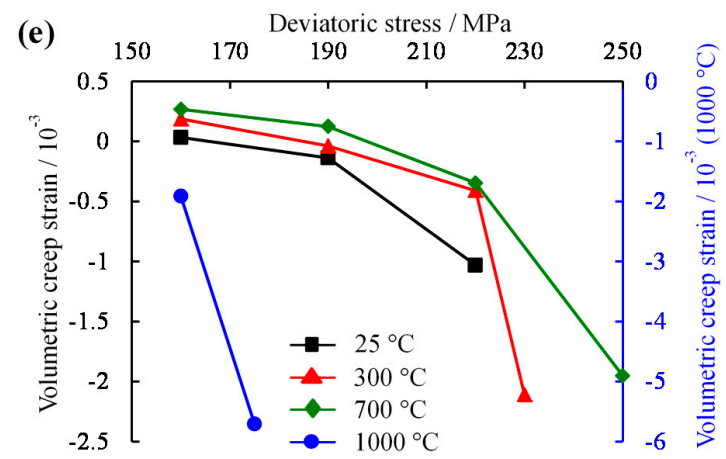

Figure 7. Volumetric creep strain-time curves under step-loading at different temperatures $\left(\sigma_{3}=25 \mathrm{MPa}\right.$ ): (a) $25{ }^{\circ} \mathrm{C}$; (b) $300{ }^{\circ} \mathrm{C}$; (c) $700{ }^{\circ} \mathrm{C}$; (d) $1000{ }^{\circ} \mathrm{C}$; (e) Relationship between volumetric creep strain and deviatoric stress.

Figure 8 illustrates the influence of temperature on the volumetric creep strains of the specimens under different compressing stresses. From Figure 8a, the creep strains of the specimens were positive for temperatures below $1000^{\circ} \mathrm{C}$ and became negative at $1000^{\circ} \mathrm{C}$. Furthermore, the negative volumetric creep strains at $1000^{\circ} \mathrm{C}$ were approximately two orders of magnitude larger than the positive ones at the other temperatures under a deviatoric stress of $160 \mathrm{MPa}$.

(a)

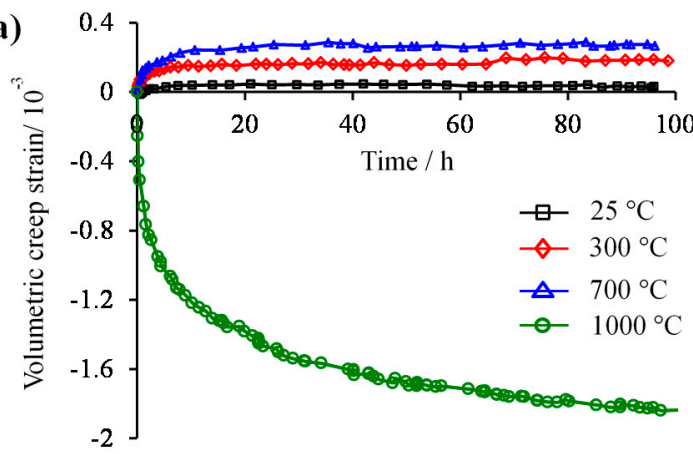

(c)

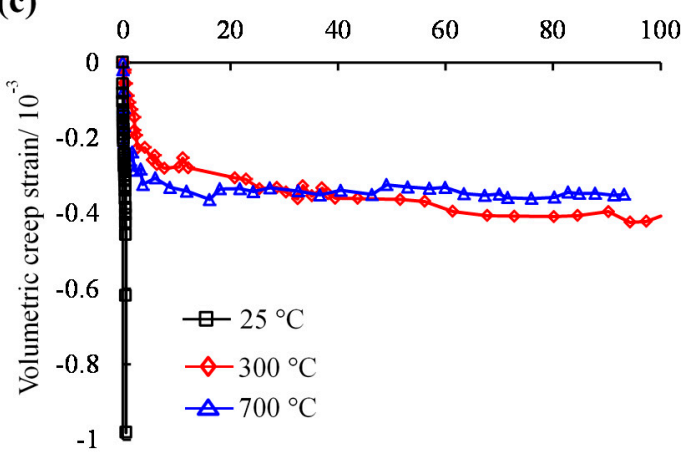

(b)

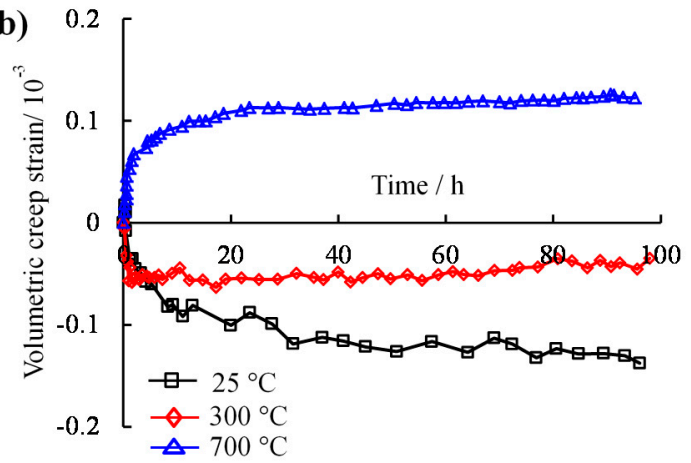

(d)

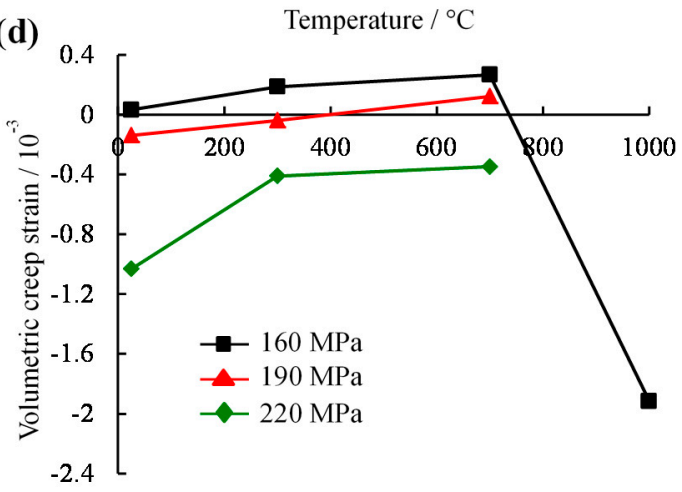

Figure 8. Relations of volumetric creep strain-time curves and temperature under identical stress condition ( $\sigma_{3}=25 \mathrm{MPa}$ ): (a) $\sigma_{1}-\sigma_{3}=160 \mathrm{MPa}$; (b) $\sigma_{1}-\sigma_{3}=190 \mathrm{MPa}$; (c) $\sigma_{1}-\sigma_{3}=220 \mathrm{MPa}$; (d) Relationship between volumetric creep strain and temperature.

This suggests that the former experienced shear dilatancy, whereas the latter experienced compression. When the partial stresses rose to $190 \mathrm{MPa}$, the two specimens at 25 and $300{ }^{\circ} \mathrm{C}$ were negative, indicating that the deformations were dominated by shear-dilatancy, whereas the specimen 
at $700{ }^{\circ} \mathrm{C}$ was still compression-dominated, or positive (Figure 8b). Because that stress level was nearer to the $\sigma_{\mathrm{p}}$ of the specimens at $25^{\circ} \mathrm{C}$, the volumetric creep slope exceeded that for $300^{\circ} \mathrm{C}$. From Figure $8 \mathrm{c}$, as the stresses increased to $220 \mathrm{MPa}$, the $25{ }^{\circ} \mathrm{C}$ specimen experienced serious shear dilation in a short time, and the others behaved similarly but did not fail. This dilation was closer to the $\sigma_{\mathrm{p}}$ of the specimen at $300{ }^{\circ} \mathrm{C}$ at that stress level, and the specimen at $300{ }^{\circ} \mathrm{C}$ with a marginally higher development strain rate in comparison with that at $700{ }^{\circ} \mathrm{C}$ can be seen in Figure 8c. The relationship between volumetric creep strain and temperature were shown in Figure 8d. It is clear that compression was given prior to expansion when temperature was below $700{ }^{\circ} \mathrm{C}$.

\section{Creep Damage Model}

Natural rocks have various scales of macro- and micro-defects, and their deformation and damage are therefore inevitably affected by those inherent flaws. In addition, their failure processes are often accompanied by the evolution, development, coalescence and interaction of cracks [13]. Therefore, rock rheological constitutive models that consider evolutionary rules of rock damage can more reasonably describe the rheological behaviors of rocks. In consequence, the following parts will introduce the damage process during the creep stage, and a creep damage model will be established.

\subsection{Construction of Creep Damage Equation}

Existing research shows that damage processes of rock materials are essentially processes of energy accumulation and dissipation [50]. Material damage is not only controlled by randomly distributed internal defects but also by internal stress and strain states. In view of the above discussions, strain energy can directly reflect the stress and strain states of rocks. Consequently, it is more reasonable to use strain energy as an internal variable to describe the damage evolution law [50].

Acoustic emission monitoring of rocks shows that energy increases substantially after the onset of the tertiary creep stage $[11,27,64]$, which is accompanied by a rapid release of strain energy. Xie et al. [63] presented a relationship between damage variable and energy dissipation:

$$
D=1-\exp \left(-\alpha\left|U^{d}-U_{0}^{d}\right|^{\beta}\right)
$$

where $U^{d}$ and $U_{0}^{d}$ are the dissipation energy leading to rock damage and the dissipated energy corresponding to the initial damage, and $\alpha$ and $\beta$ are parameters related to material properties.

According to previous research [65], the strain energy can be expressed as.

$$
U=\int_{0}^{\varepsilon_{i j}} \sigma_{i j} d \varepsilon_{i j}
$$

where $\sigma_{i j}$ and $\varepsilon_{i j}$ are stress and strain, and $(i j=1,2,3)$.

This article presents a damage evolution equation based on strain energy, which is expressed as Equation (3). In addition, its evolution law is shown in Figure 9.

$$
\left\{\begin{array}{l}
D=0 \quad\left(U<U_{0}\right) \\
D=\frac{U-U_{0}}{\alpha U_{0}} \quad\left(U_{0} \leq U<(1+\alpha) U_{0}\right) \\
D=1 \quad U \geq(1+\alpha) U_{0}
\end{array}\right.
$$

where $U$ is the strain energy, $U_{0}$ is the critical strain energy corresponding to the initial damage, and the strain energy can be calculated using Equation (2), $\alpha$ is a parameter related to the material creep property and always exceeds $0 . D$ is the damage variable. When $D=0$, no damage occurs during the creep process. $D=1$ corresponds to materials that suffer only creep failure. Therefore, $0<D<1$ corresponds to materials with various extents of damage during the creep process.

The Burgers model is widely used to describe the creep deformation of rock, and employs Maxwell and Kelvin bodies in series. However, it cannot reflect accelerating creep behavior. Therefore, 
we present a creep damage model based on Burgers model to completely describe the entire creep process. The creep damage model can reflect the entire creep stage, unlike the typical Burgers model, as shown in Figure 10.

The Burgers model's equations of state can be written as:

$$
\left\{\begin{array}{l}
S_{\mathrm{e}}=2 G_{\mathrm{M}} e_{\mathrm{e}} \\
S_{\mathrm{v}}=2 \eta_{\mathrm{M}} \dot{e}_{\mathrm{v}} \\
S_{\mathrm{ve}}=2 G_{\mathrm{K}} e_{\mathrm{ve}}+2 \eta_{\mathrm{K}} \dot{e}_{\mathrm{ve}} \\
S_{i j}=S_{\mathrm{e}}=S_{\mathrm{v}}=S_{\mathrm{ve}} \\
e_{i j}=e_{\mathrm{e}}+e_{\mathrm{v}}+e_{\mathrm{ve}}
\end{array}\right.
$$

where $S_{i j}$ is the partial stress tensor, and $S_{\mathrm{e}}, S_{\mathrm{v}}$ and $S_{\mathrm{ve}}$ are the partial stress tensors for elastic, viscous and visco-elastic bodies respectively. $e_{i j}$ is the partial strain tensor, and $e_{\mathrm{e}} e_{\mathrm{v}}$ and $e_{\mathrm{ve}}$ are the corresponding partial strain tensors. $G_{\mathrm{M}}$ and $G_{\mathrm{K}}$ are the shear moduli. $\eta_{\mathrm{M}}$ and $\eta_{\mathrm{K}}$ are the viscosity coefficients. When the confining pressures $\sigma_{2}$ equals $\sigma_{3}$, the spheric stress $\left(\sigma_{\mathrm{m}}\right)$ and spheric strain $\left(\varepsilon_{\mathrm{m}}\right)$ can be expressed as Equations (5) and (6), and the axial deviatoric stress $\left(S_{11}\right)$ can be written as Equation (7):

$$
\begin{gathered}
\sigma_{\mathrm{m}}=\frac{1}{3}\left(\sigma_{1}+\sigma_{2}+\sigma_{3}\right)=\frac{\left(\sigma_{1}-\sigma_{3}\right)+3 \sigma_{3}}{3} \\
\varepsilon_{\mathrm{m}}=\frac{\sigma_{\mathrm{m}}}{3 K}=\frac{\sigma_{1}+2 \sigma_{3}}{9 K}=\frac{\left(\sigma_{1}-\sigma_{3}\right)+3 \sigma_{3}}{9 K}, \text { and } \\
S_{11}=\sigma_{1}-\sigma_{\mathrm{m}}=\frac{2}{3}\left(\sigma_{1}-\sigma_{3}\right)
\end{gathered}
$$

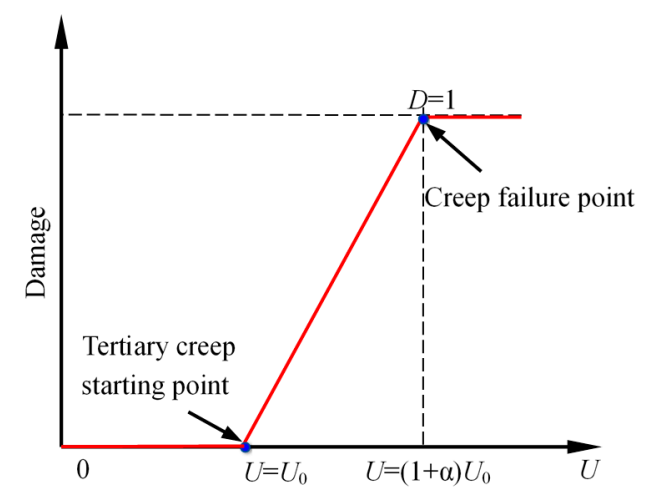

Figure 9. Rock damage evolution trend.

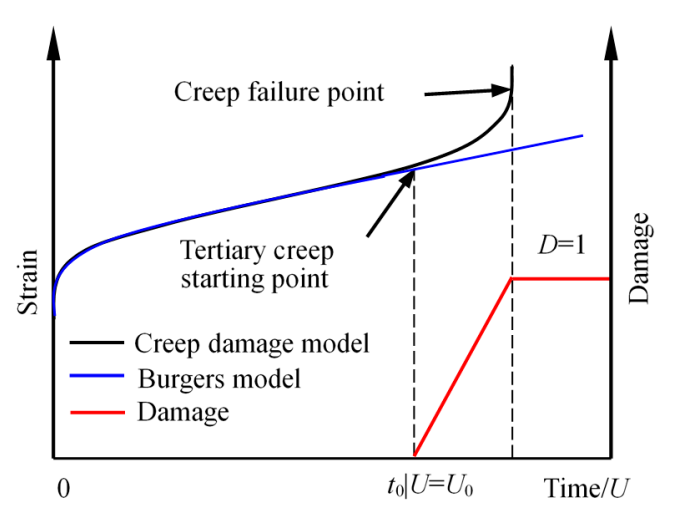

Figure 10. Rock creep damage model and Burgers model. 
Supposing the volume of material is changed by the spheric stress, and the shape of material is just changed by the differential stress tensor. Moreover, the partial stress tensor can only influence the creep deformation of material [66]. As a consequence, Burgers creep equation can be expressed as Equation (8):

$$
e_{i j}=\frac{S_{i j}}{2 G_{\mathrm{K}}}+\frac{S_{i j}}{2 G_{\mathrm{K}}}\left(1-\exp \left(-\frac{G_{\mathrm{K}}}{\eta_{\mathrm{K}}} t\right)\right)+\frac{S_{i j}}{2 \eta_{\mathrm{M}}} t
$$

Subsequently, the Burgers equation under traditional triaxial compression stress $\left(\sigma_{2}=\sigma_{3}\right)$ can be written as:

$$
\varepsilon_{1}=\frac{\left(\sigma_{1}-\sigma_{3}\right)+3 \sigma_{3}}{9 K}+\frac{\left(\sigma_{1}-\sigma_{3}\right)}{3 G_{\mathrm{M}}}+\frac{\left(\sigma_{1}-\sigma_{3}\right)}{3 G_{\mathrm{K}}}\left(1-\exp \left(-\frac{G_{\mathrm{K}}}{\eta_{\mathrm{K}}} t\right)\right)+\frac{\left(\sigma_{1}-\sigma_{3}\right)}{3 \eta_{\mathrm{M}}} t
$$

In Equation (9), $K$ and $G_{M}$ can be identified using experimental $\varepsilon_{0}$ data, where $\varepsilon_{0}$ is the value of the axial strain under each deviatoric stress. The other parameters, including $G_{K}, \eta_{M}$ and $\eta_{K}$, can be obtained using nonlinear the least square method. In passing, the shear modulus $G_{M}$ and bulk modulus $K$ can be calculated from:

$$
\begin{gathered}
K=\frac{E}{3(1-2 \mu)}, \text { and } \\
G_{\mathrm{M}}=\frac{\sigma_{1}-\sigma_{3}}{3\left(\varepsilon_{0}-\frac{\left(\sigma_{1}-\sigma_{3}\right)+3 \sigma_{3}}{9 K}\right)}
\end{gathered}
$$

where $E$ and $\mu$ are the elastic modulus and Poisson's ratio of the rock material, respectively.

During the creep process, various degrees of inner damage in rock arise that show the degradation of the strength and deformation parameters. Assuming that rock only suffers isotropic damage in rheological processes, the creep mechanicals parameters considering creep damage can be expressed as:

$$
\Omega^{\mathrm{cd}}=\Omega^{0}(1-D)
$$

where $\Omega^{0}$ is the rock's initial creep parameter, and $\Omega^{\mathrm{cd}}$ is the creep parameter after creep damage. Burgers model considering creep damage, as shown in Figure 11, can therefore be expressed as

$$
\varepsilon_{1}=\frac{\left(\sigma_{1}-\sigma_{3}\right)+3 \sigma_{3}}{9 K}+\frac{\left(\sigma_{1}-\sigma_{3}\right)}{3 G_{\mathrm{M}}(1-D)}+\frac{\left(\sigma_{1}-\sigma_{3}\right)}{3 G_{\mathrm{K}}(1-D)}\left(1-\exp \left(-\frac{G_{\mathrm{K}}(1-D)}{\eta_{\mathrm{K}}(1-D)} t\right)\right)+\frac{\left(\sigma_{1}-\sigma_{3}\right)}{3 \eta_{\mathrm{M}}(1-D)} t
$$



Figure 11. Creep damage model of Burgers.

\subsection{Sensitivity Analysis of the Damage Parameters}

Figure 12 shows the influences of $U_{0}$ and $\alpha$ on the strain curve of the red sandstone. From Figure 12, it can be seen that parameters $U_{0}$ and $\alpha$ greatly impacted the time-dependent strain curve. In particular, with the increase in parameter $U_{0}$, the attenuation and steady-creep stage durations increased when the remaining parameters in the creep damage model were kept constant, which indicates that the durations of the initial and secondary creep stages depended on $U_{0}$. Similarly, the accelerating creep stage duration increased with increasing $\alpha$, indicating that $\alpha$ mainly impacted the creep failure time. 

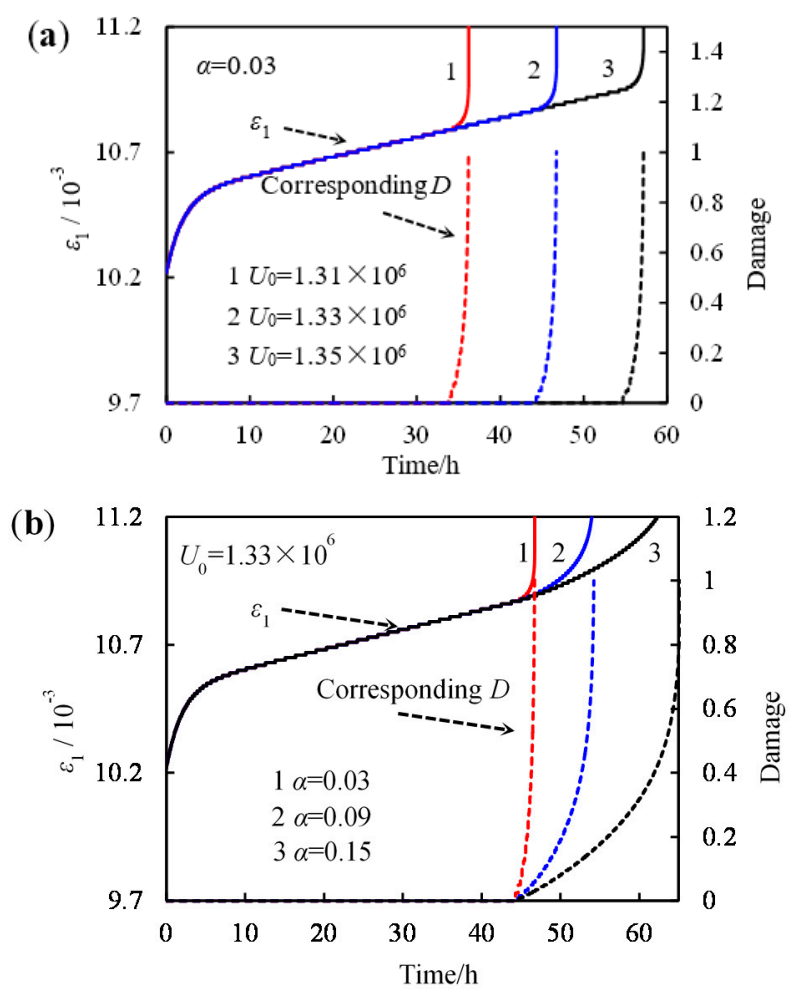

Figure 12. Influence of $U_{0}$ and $\alpha$ to strain curve and damage: (a) $\alpha=0.03$; (b) $U_{0}=1.33 \times 10^{6}$ (Note: $K=10 \mathrm{GPa}, \mathrm{G}_{\mathrm{M}}=10 \mathrm{GPa}, \mathrm{G}_{\mathrm{K}}=250 \mathrm{GPa}, \eta_{\mathrm{M}}=10,000 \mathrm{GPa} \cdot \mathrm{h}$ and $\left.\eta_{\mathrm{K}}=500 \mathrm{GPa} \cdot \mathrm{h}\right)$.

\subsection{Model Validation}

As mentioned earlier, the parameters of Burgers can be determined easily. We will next present a secondary development using FLAC ${ }^{3 \mathrm{D}}$ (ITASCA Consulting China Ltd., Wuhan, China) to facilitate the calculations of $\alpha$ and $U_{0}$. The damage constitution equation of Kelvin in FLAC ${ }^{3 \mathrm{D}}$ can be written as:

$$
S=e_{\mathrm{K}} G_{\mathrm{K}}(D)+\dot{e}_{\mathrm{K}} \eta_{\mathrm{K}}(D)
$$

where $S$ is the deviatoric stress, $e_{\mathrm{K}}$ is the Kelvin partial strain, $G_{\mathrm{K}}$ is the shear modulus of the Kelvin body, and $\eta_{\mathrm{K}}$ is the Kelvin viscosity coefficient. The difference expression of this equation can be written as:

$$
\begin{gathered}
e_{\mathrm{K}}^{N}=e_{\mathrm{K}}^{O}+\left(\bar{S}-G_{\mathrm{K}}(D) \bar{e}_{\mathrm{K}}\right) \frac{\Delta t}{\eta_{\mathrm{K}}(D)}, \text { and } \\
\bar{S}=\frac{S^{N}+S^{O}}{2}, \bar{e}_{\mathrm{K}}=\frac{e_{\mathrm{K}}^{N}+e_{\mathrm{K}}^{O}}{2}
\end{gathered}
$$

where $\Delta t$ is the creep time increment step, and $S^{N}$ and $S^{O}$ are the new and old deviatoric stresses of an increment step of creep time, respectively. Correspondingly, $e_{\mathrm{K}}^{N}$ and $e_{\mathrm{K}}^{O}$ are the new and old deviatoric strains of an increment step of creep time, respectively.

Similarly, the Maxwell damage constitution equation in FLAC $^{3 \mathrm{D}}$ can be written as:

$$
\dot{e}_{\mathrm{M}}=\frac{\dot{S}}{G_{\mathrm{M}}(D)}+\frac{S}{\eta_{\mathrm{M}}(D)}
$$


where $e_{\mathrm{M}}$ is the Maxwell partial strain, $G_{\mathrm{M}}$ is the shear modulus of the Maxwell body, and $\eta_{\mathrm{M}}$ is the Maxwell viscosity coefficient. The difference expression of this equation can be written as

$$
e_{\mathrm{M}}^{N}=e_{\mathrm{M}}^{O}+\frac{S^{N}-S^{O}}{G_{\mathrm{M}}(D)}+\frac{\Delta t}{\eta_{\mathrm{M}}(D)} \frac{S^{N}+S^{O}}{2}
$$

where $\Delta t$ is the increment step of creep time, and $S^{N}$ and $S^{O}$ are the new and old deviatoric stresses of an increment step of creep time, respectively. Correspondingly, $e_{\mathrm{M}}^{N}$ and $e_{\mathrm{M}}^{O}$ are the new and old deviatoric strains of an increment step of creep time, respectively. In Burgers model, the difference of partial strain between new and old values can calculated as:

$$
e^{N}-e^{O}=e_{\mathrm{K}}^{N}-e_{\mathrm{K}}^{O}+e_{\mathrm{M}}^{N}-e_{\mathrm{M}}^{O}
$$

The strain increment of the Kelvin body can be calculated using Equation (20):

$$
e_{\mathrm{K}}^{N}=\frac{1}{A}\left[B e_{\mathrm{K}}^{O}+\left(S^{N}+S^{O}\right) \frac{\Delta t}{2 \eta_{\mathrm{K}}(D)}\right]
$$

where:

$$
A=1+\frac{G_{\mathrm{K}}(D) \Delta t}{2 \eta_{\mathrm{K}}(D)}, \text { and } B=1-\frac{G_{\mathrm{K}}(D) \Delta t}{2 \eta_{\mathrm{K}}(D)}
$$

Similarly, the strain increment of the Maxwell body can be calculated using Equation (22):

$$
S^{N}=\frac{1}{X}\left[\left(e^{N}-e^{O}\right)-\left(\frac{B}{A}-1\right) e_{\mathrm{K}}^{O}+Y \cdot S^{O}\right]
$$

where:

$$
X=\frac{1}{G_{\mathrm{M}}(D)}+\frac{\Delta t}{2 \eta_{\mathrm{M}}(D)}+\frac{\Delta t}{2 \eta_{\mathrm{K}}(D) A}, \text { and } Y=\frac{1}{G_{\mathrm{M}}(D)}-\frac{\Delta t}{2 \eta_{\mathrm{M}}(D)}-\frac{\Delta t}{2 \eta_{\mathrm{K}}(D) A}
$$

In Equations (22) and (23), the increment of stress can be calculated according to the increment of strain. Numerical solutions can be obtained by satisfying all the boundary conditions on each side through multiple iterations.

The creep parameters can be deteriorated by introducing the cumulative damage variable after obtaining the linear difference equation of Burgers model. The strain energy in the creep process can be calculated using Equation (24):

$$
U=\sum_{t} \sum_{i=1}^{3} \frac{S_{i}^{N}+S_{i}^{O}}{2}\left(e_{i}^{N}-e_{i}^{O}\right)
$$

It is supposed that there is no creep deformation or damage under conditions of hydrostatic pressure. Therefore, the creep parameters can be expressed as:

$$
\left\{\begin{array}{l}
G_{\mathrm{M}}(D)=G_{\mathrm{M}} \cdot(1-D) \\
\eta_{\mathrm{M}}(D)=\eta_{\mathrm{M}} \cdot(1-D) \\
G_{\mathrm{K}}(D)=G_{\mathrm{K}} \cdot(1-D) \\
\eta_{\mathrm{K}}(D)=\eta_{\mathrm{K}} \cdot(1-D)
\end{array}\right.
$$

In view of the above discussions, the nonlinear creep damage model based on the Burgers model can be implemented through numerical simulations. The parameters of the Burgers model based on experimental data have been determined. Concretely speaking, $U$ can be calculated according to the calculated parameters of the Burgers model by numerical simulation. $U_{0}$ at the onset of tertiary creep based on tested data can then be determined from the numerical calculation results. Finally, $\alpha$ can be 
adjusted according to the experimentally characteristic of the accelerating creep based on experiment. The calculation and fitting results are shown in Table 2 and Figure 13.

Table 2. Parameters of creep damage model in creep tests $\left(\sigma_{3}=25 \mathrm{MPa}\right)$.

\begin{tabular}{|c|c|c|c|c|c|c|c|c|c|c|c|}
\hline$T /{ }^{\circ} \mathrm{C}$ & $P / \mathrm{MPa}$ & $P / \sigma_{\mathrm{p}} / \%$ & K/GPa & $G_{\mathrm{M}} / \mathrm{GPa}$ & $\begin{array}{c}\eta_{\mathrm{M}} \times 10^{3} \\
/ \mathrm{GPa} \cdot \mathrm{h}\end{array}$ & $G_{\mathrm{K}} / \mathrm{GPa}$ & $\eta_{\mathrm{K}} / \mathrm{GPa} \cdot \mathrm{h}$ & $\alpha$ & $U_{0} / \mathrm{J} \mathrm{mm}^{-1}$ & $R^{2}$ & $Q \times 10^{-3}$ \\
\hline \multirow{3}{*}{25} & 160 & 68 & 20.09 & 12.05 & 76.93 & 407.09 & 956.58 & & & 0.99 & 1.53 \\
\hline & 190 & 81 & 19.41 & 11.64 & 53.19 & 325.88 & 826.49 & & & 0.99 & 3.31 \\
\hline & 220 & 94 & 18.51 & 11.11 & 0.18 & 590.20 & 21.54 & 0.065 & $9.86 \times 10^{5}$ & 0.98 & 10.32 \\
\hline \multirow{2}{*}{300} & 160 & 65 & 19.30 & 11.58 & 84.83 & 279.28 & 498.57 & & & 0.99 & 1.03 \\
\hline & 190 & 78 & 18.92 & 11.35 & 66.63 & 260.97 & 561.20 & & & 0.99 & 1.37 \\
\hline \multirow{3}{*}{700} & 160 & 55 & 14.29 & 8.57 & 79.98 & 172.57 & 289.35 & & & 0.99 & 7.28 \\
\hline & 190 & 65 & 14.29 & 8.58 & 41.99 & 166.80 & 282.35 & & & 0.98 & 2.36 \\
\hline & 220 & 76 & 14.25 & 8.55 & 41.56 & 100.77 & 137.15 & & & 0.98 & 5.39 \\
\hline 1000 & 160 & 77 & 6.37 & 3.82 & 0.79 & 40.18 & 77.37 & & & 0.98 & 3.67 \\
\hline
\end{tabular}

(a)

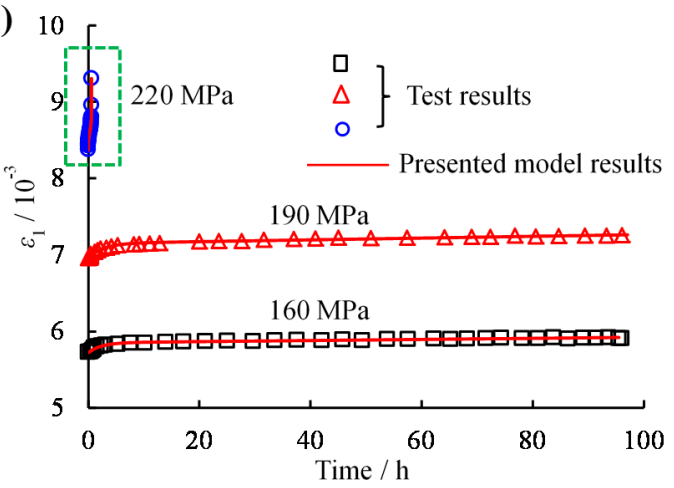

(c) 1



(b)

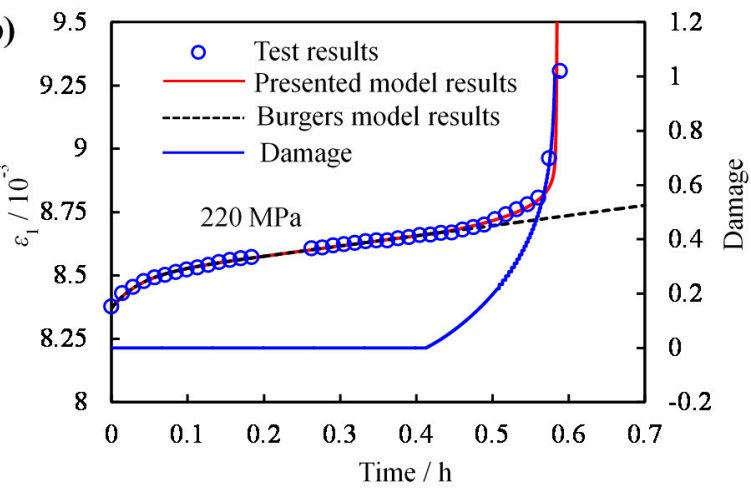

(d)

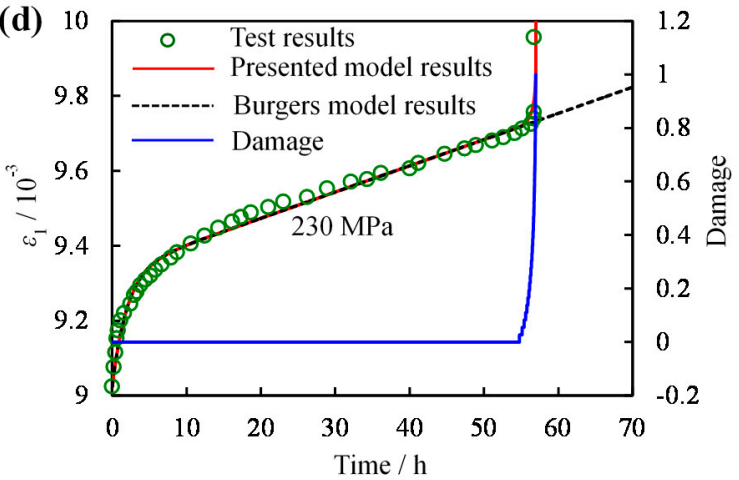

Figure 13. Comparison between the modeling and experimental results under confining of $25 \mathrm{MPa}$ : (a) $25{ }^{\circ} \mathrm{C}$; (b) partial enlarged for $\sigma_{1}-\sigma_{3}=220 \mathrm{MPa}$; (c) $300{ }^{\circ} \mathrm{C}$; (d) partial enlarged for $\sigma_{1}-\sigma_{3}=230 \mathrm{MPa}$.

From Figure 13, the creep damage model curves agree well with the experimental data, and the modified model is therefore reasonable and simple. According to Figure 13b,d, the Burgers and creep damage models produced the same fitting results during the primary and steady creep state stages. However, the creep damage model accurately reproduced the tertiary creep phase, whereas Burgers model was unable to describe the accelerated creep process when compared with the fitting results. In addition, as $U$ increased above $U_{0}, D$ began to gradually increase from 0 to 1 , which indicates that the dominant damage induced by cracks was augmented by creep deformation. 


\section{Discussion}

\subsection{Relationship between the Axial and Lateral Creep Strain}

Figure 14 shows the relations between the axial and the lateral creep strains from multi-stepping creep tests of specimens at various temperatures under a $\sigma_{3}$ of $25 \mathrm{MPa}$. It is worth noting that a monotonic linear correlation between the axial and lateral creep strains could be determined for each stress condition. It should be emphasized that the negative sign represents the direction of lateral expansion. From Figure 14, the slopes of the fit lines increased gradually with increasing deviatoric stress, which means lateral deformation became more obvious as the deviatoric stress increased.
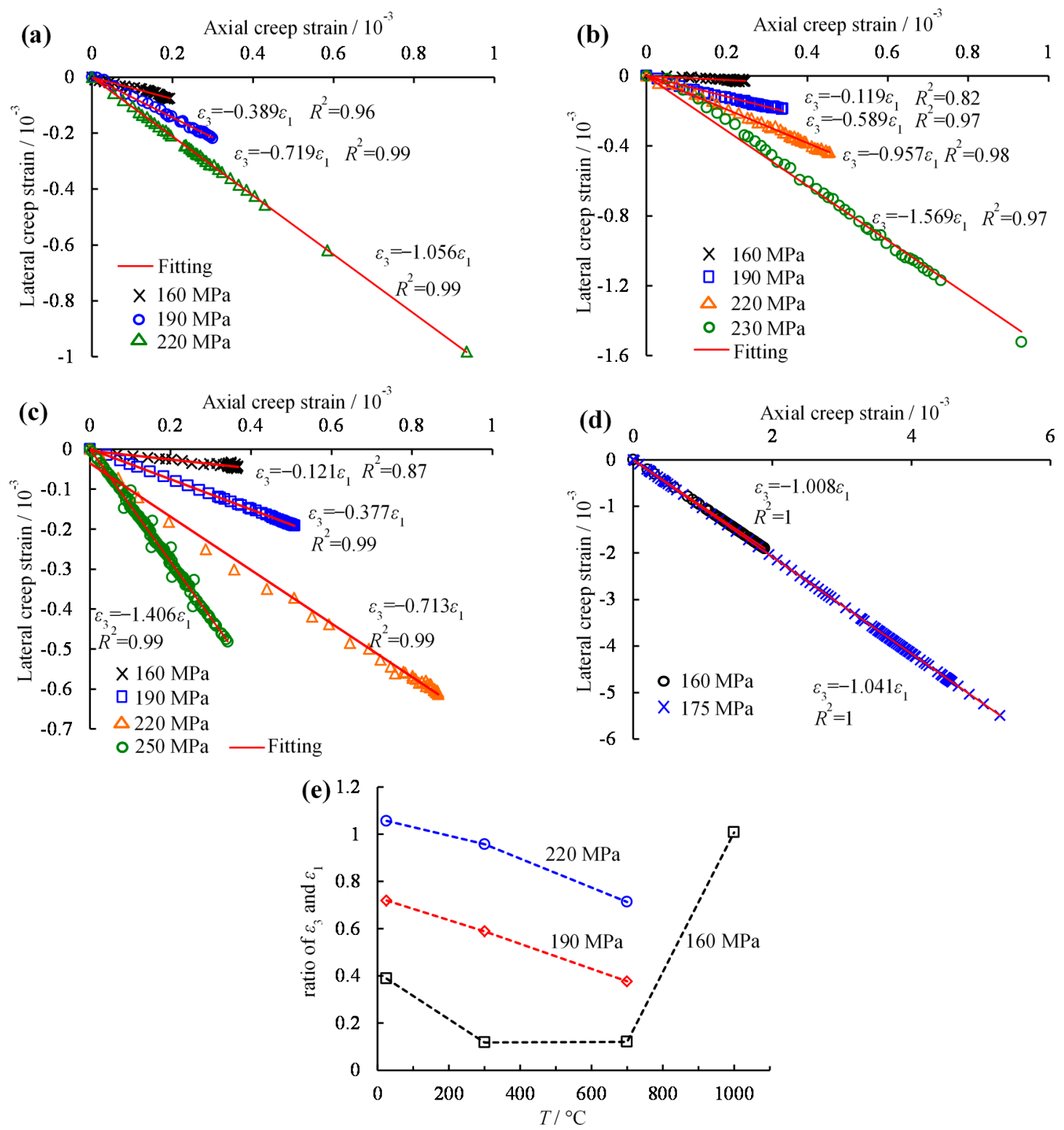

Figure 14. Relationships between the axial creep strain and the lateral creep strain at different temperatures: (a) $25^{\circ} \mathrm{C}$; (b) $300{ }^{\circ} \mathrm{C}$; (c) $700{ }^{\circ} \mathrm{C}$; (d) $1000{ }^{\circ} \mathrm{C}$; (e) Relation between the slope of fitting line and temperature.

Comparing the slopes of the fit lines at different temperatures in Figure $14 \mathrm{a}-\mathrm{d}$, under a deviatoric stress of $160 \mathrm{MPa}$, the slope first decreased from 0.389 at $25^{\circ} \mathrm{C}$ to 0.119 at $300{ }^{\circ} \mathrm{C}$ and then increased from 0.121 to 1.008 as the temperature was elevated from $700{ }^{\circ} \mathrm{C}$ to $1000{ }^{\circ} \mathrm{C}$, as shown in Figure $14 \mathrm{e}$. 
However, because the $\sigma_{\mathrm{p}}$ of the specimen at $1000{ }^{\circ} \mathrm{C}$ was the lowest $(207.36 \mathrm{MPa})$, the specimen experienced creep rupture under a partial stress of $175 \mathrm{MPa}$. Therefore, the deformations under $190 \mathrm{MPa}$ and $220 \mathrm{MPa}$ could not be obtained, and the corresponding slope value also could not be calculated. As the temperature increased from room temperature to $700{ }^{\circ} \mathrm{C}$, the slopes of the fit lines under deviatoric stresses of 190 and $220 \mathrm{MPa}$ decreased linearly.

\subsection{Thermal Influence on Parameters of Creep Model}

This article mainly focusses the influence of temperature on creep deformation under same stress conditions. The presented creep damage model can also well describe the entire creep process. Therefore, it is necessary to discuss the influence of temperature on the creep parameters of the model under identical stress levels. Because the $\sigma_{\mathrm{c}}$ of each specimen differed at various temperatures, it is hard to fully consider the influence of temperature on creep parameters under each deviatoric stress. Accordingly, thermal effects on creep parameters can be investigated under common deviatoric stresses of 160, 190 and $220 \mathrm{MPa}$.

From Figure 15a, $K$ decreased gradually with increasing temperature for specimens under 160, 190 and $220 \mathrm{MPa}$. It indicates that with increasing temperature, the variation in volume was more obvious under spherical stress (total stress can be divide into spherical stress and partial stress), the volume of material was changed by the spherical stress tensor, and the shape of the material was only changed by the differential stress tensor [65]. It is worth noting that the data used for this test were inadequate due to the specimens at $1000{ }^{\circ} \mathrm{C}$ under 190 and $220 \mathrm{MPa}$ which were above their $\sigma_{\mathrm{p}}$. Hence, the fits for the results from each specimen under $160 \mathrm{MPa}$ are presented herein. Similarly, Figure $15 \mathrm{~b}$ shows the variation in $G_{M}$ with temperature. $K$ and $G_{M}$ showed the same trend because of the calculation using uniform $E$ and $\mu$ according to the instantaneous axial strain. Those two parameters reflect instantaneous response when loading is applied, which is inversely proportional to the instantaneous strain. Figure 15c shows that the viscosity coefficient of the Maxwell body changed with temperature under the various stress levels. It first increased as the temperature rose to $300{ }^{\circ} \mathrm{C}$ and then decreased as the temperature rose above $300{ }^{\circ} \mathrm{C}$. In particular, it suddenly decreased at $1000{ }^{\circ} \mathrm{C}$ under $160 \mathrm{MPa}$. This parameter reflects the state of steady creep and is strongly related to the ratio of applied stress and $\sigma_{\mathrm{p}}$, which is proportional to the ratio. In Figure $15 \mathrm{~d}$, the shear modulus of the Kelvin body was linearly related to temperature, which decreased with increasing temperature. $G_{\mathrm{K}}$ mainly affected the time from attenuation creep to steady-state creep. In Figure 15e, $\eta_{\mathrm{K}}$ decreased nonlinearly with increasing temperature, with the exception of the specimen at $25{ }^{\circ} \mathrm{C}$ under a $\sigma_{\mathrm{c}}$ of $220 \mathrm{MPa}$. This occurred because the specimens failed with large creep deformation in a short time. Furthermore, the viscosity coefficient of the Kelvin body mainly affected the instantaneous creep rate, which had an inversely proportion relationship.
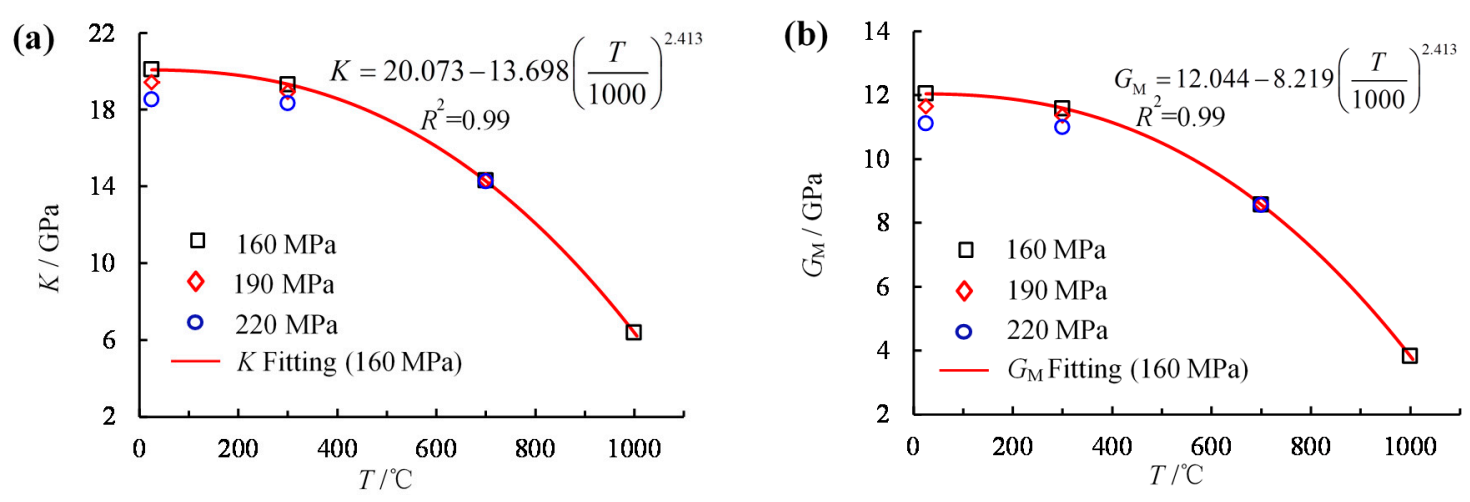

Figure 15. Cont. 

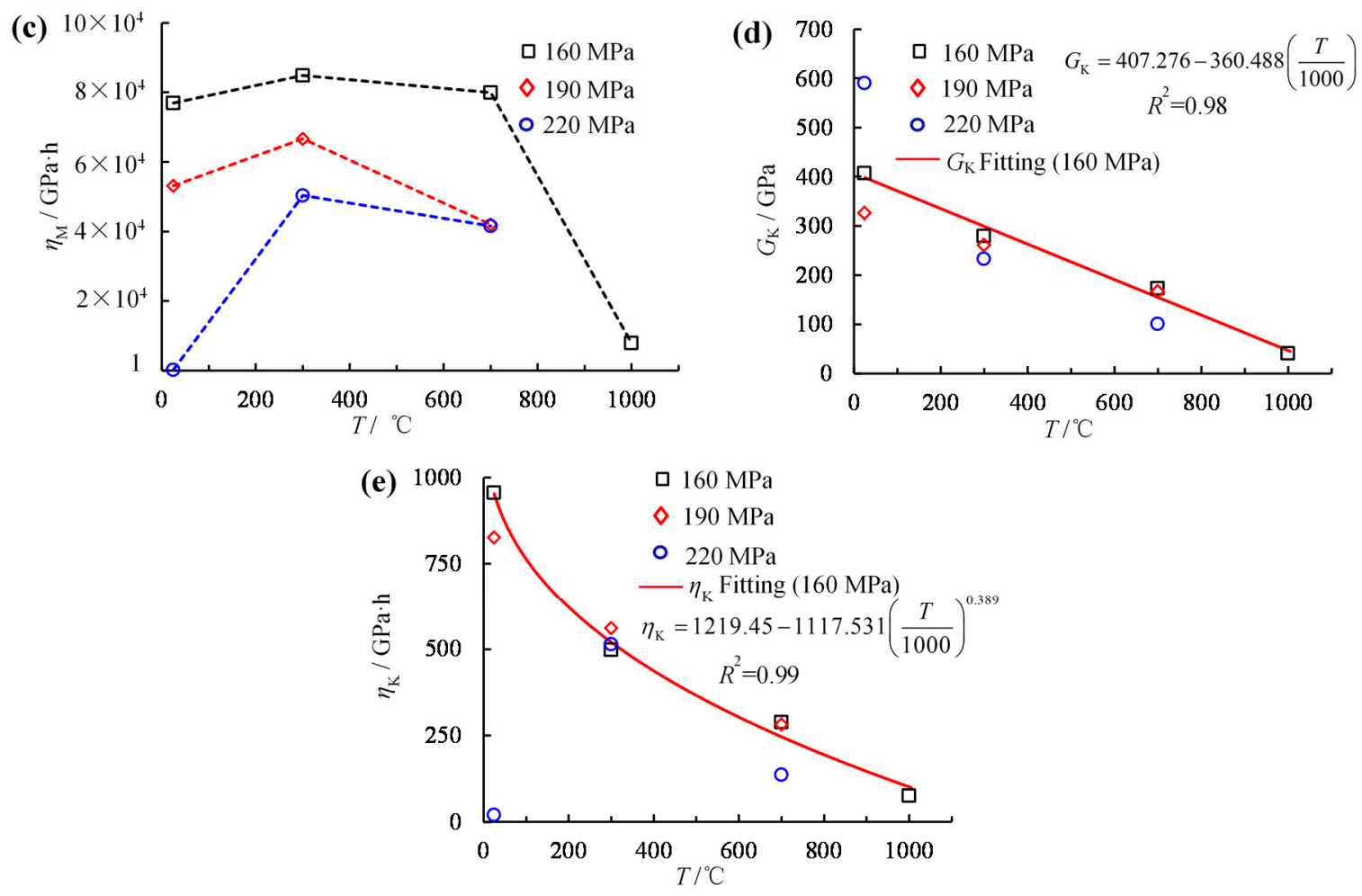

Figure 15. Relation between creep parameters and temperature: (a) $K ;(\mathbf{b}) G_{\mathrm{M}} ;(\mathbf{c}) \eta_{\mathrm{M}} ;(\mathbf{d}) G_{\mathrm{K}} ;(\mathbf{e}) \eta_{\mathrm{K}}$.

Accordingly, the creep damage model considering thermal influence can be written as Equation (26) if the fitting relationships between the creep parameters and temperature can be obtained according to Equation (13):

$$
\varepsilon_{1}=\frac{\left(\sigma_{1}-\sigma_{3}\right)+3 \sigma_{3}}{9 K(T)}+\frac{\left(\sigma_{1}-\sigma_{3}\right)}{3 G_{\mathrm{M}}(T)(1-D)}+\frac{\left(\sigma_{1}-\sigma_{3}\right)}{3 G_{\mathrm{K}}(T)(1-D)}\left(1-\exp \left(-\frac{G_{\mathrm{K}}(T)(1-D)}{\eta_{\mathrm{K}}(T)(1-D)} t\right)\right)+\frac{\left(\sigma_{1}-\sigma_{3}\right)}{3 \eta_{\mathrm{M}}(T)(1-D)} t
$$

\subsection{Thermal Influence on Creep Behavior}

High temperatures seriously deteriorate the degree of consolidation and amplified the distance between grains, especially via boundary and thermally-induced cracks. Therefore, the total amount of strain that can be accumulated increases with increasing temperature. It can explain the phenomenon whereby the instantaneous strain and time-based axial creep strain of red sandstone increased with increasing temperature under identical deviatoric stresses. The radius creep strain under same the stress conditions (e.g., deviatoric stresses of 160 and $190 \mathrm{MPa}$ ) first decreased as the temperature increased from $25{ }^{\circ} \mathrm{C}$ to $300{ }^{\circ} \mathrm{C}$ and then increased as temperature rose above $300{ }^{\circ} \mathrm{C}$ because the work due to the external force was mainly used for axial deformation, which was the main source of compression of the mineral particles and adjustment and closure of boundary cracks, and there was therefore little available work to induce lateral dilatancy deformation. As the temperature was increased to $700{ }^{\circ} \mathrm{C}$, energy was required to close the thermally-induced cracks in addition to compressing the grains and closing the boundary cracks. Furthermore, the reduction in consolidation degree and ductility enhancement could have enhanced the degree of shear dilatancy, especially for the specimen at $1000{ }^{\circ} \mathrm{C}$, whose bearing capacity decreased suddenly. When the applied stress (e.g., deviatoric stress $=160 \mathrm{MPa}$ ) exceeded its $\sigma_{\mathrm{cd}}$, the axial bearing capacity was unable to consume much energy from the applied stress, so that the energy shifted to the lateral dilatancy part. Hence, its lateral creep strain showed large discrepancies when compared to the other thermal treated specimens. This can also explain the phenomenon whereby the volumetric creep strain shifted from axial 
compression-dominant to shear dilatancy-dominant as the temperature was increased. The volume creep strain mainly reflected the competing states of axial compression and lateral dilatancy.

Under increasing compressive stress, rock experiences differing degrees of nucleation, propagation, interaction and coalescence at various crack scale [67]. Hence, a specimen deforms promptly when different stresses are applied. While keeping the loading constant, the deformation will increase with increasing time on the basis of the former distortion. There are both elastic and viscous plastic deformations of the red sandstone matrix, and time-dependent microcrack propagation is generally coupled during the two processes. Another explanation is due to stress corrosion [60]. All of the above reasons promote the shear dilatancy deformation as stress level and time are increased.

Inspired by the form of normalized stress [30], herein termed the critical stress ratio (CSR), is expressed as:

$$
\mathrm{CSR}=\frac{\sigma_{\mathrm{c}}-\sigma_{\mathrm{r}}}{\sigma_{\mathrm{p}}-\sigma_{\mathrm{r}}}
$$

where $\sigma_{\mathrm{p}}$ is the peak strength, $\sigma_{\mathrm{r}}$ is the residual strength, and $\sigma_{\mathrm{c}}$ is the creep failure stress respectively.

From Figure 16, it can be seen that the critical stress ratio decreased with increasing temperature. To be specific, it decreased from 0.89 at room temperature to 0.44 at $1000{ }^{\circ} \mathrm{C}$, and we can conclude that the temperature heavily affected the critical stress ratio, such that creep failure more easily occurred at higher temperatures. As the deviatoric stress increased to $\sigma_{\mathrm{c}}$ (reaching to the CSR), the specimen experienced failure sliding along a shear fault.

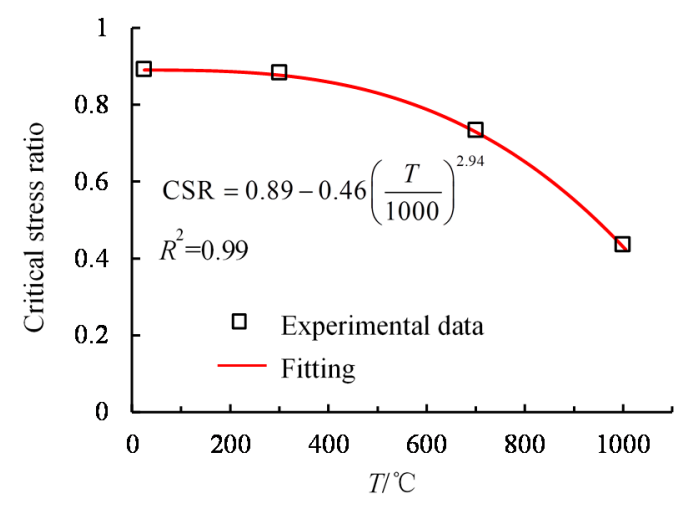

Figure 16. Critical stress ratio versus temperature.

\subsection{Thermal Influence on Microstructure/Composition}

In order to analyze the microstructure and composition of specimens before and after heating, observation by optical and polarizing microscopy (Figures 17 and 18) and X-ray diffraction (XRD) (Figure 19) were conducted after four temperatures $\left(25,300,700\right.$ and $\left.1000{ }^{\circ} \mathrm{C}\right)$ were applied. Figure 17 shows the microscopic structure of specimens after the different thermal treatments by optical microscopy. It is clear that the color variation of the specimen was marked, which varied from gray red to bright red, and then to reddish with increasing temperature. This indicated that mineral composition in specimens changed with the temperature. Moreover, thermally-induced cracks appeared at temperature above $700^{\circ} \mathrm{C}$, as shown in Figure $17 \mathrm{c}, \mathrm{d}$. 

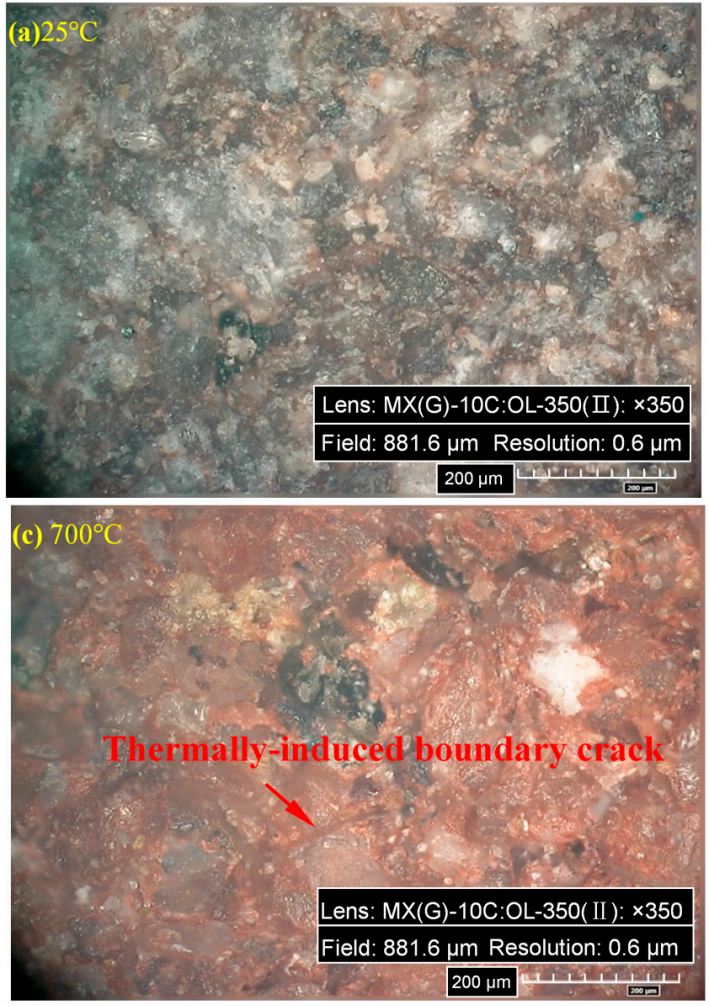
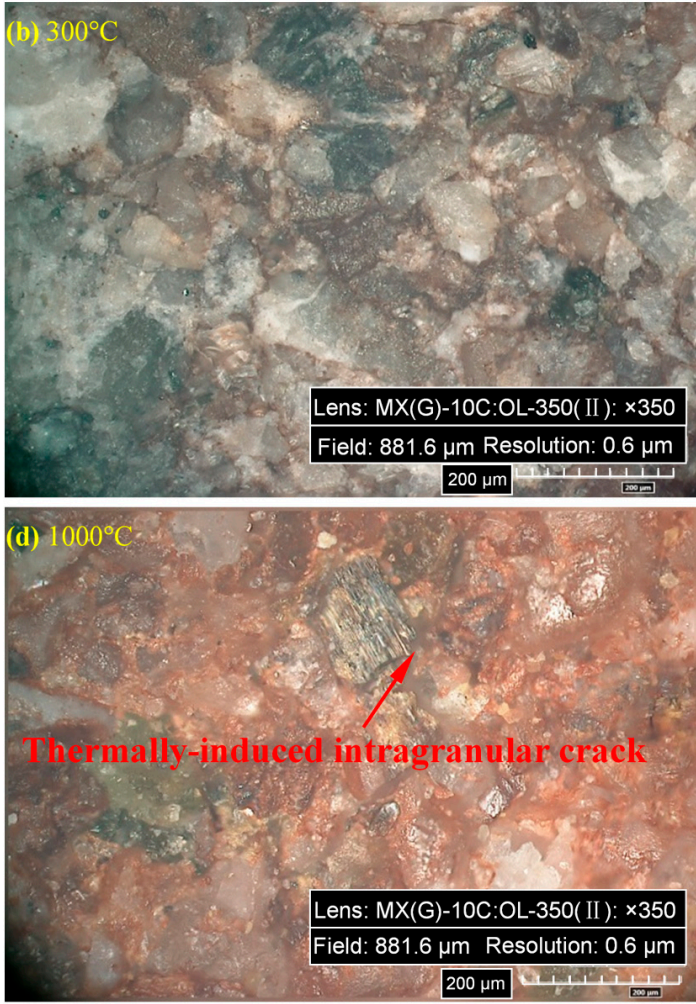

Figure 17. Microscopic structure of red sandstone (optical microscopy) used in this research.
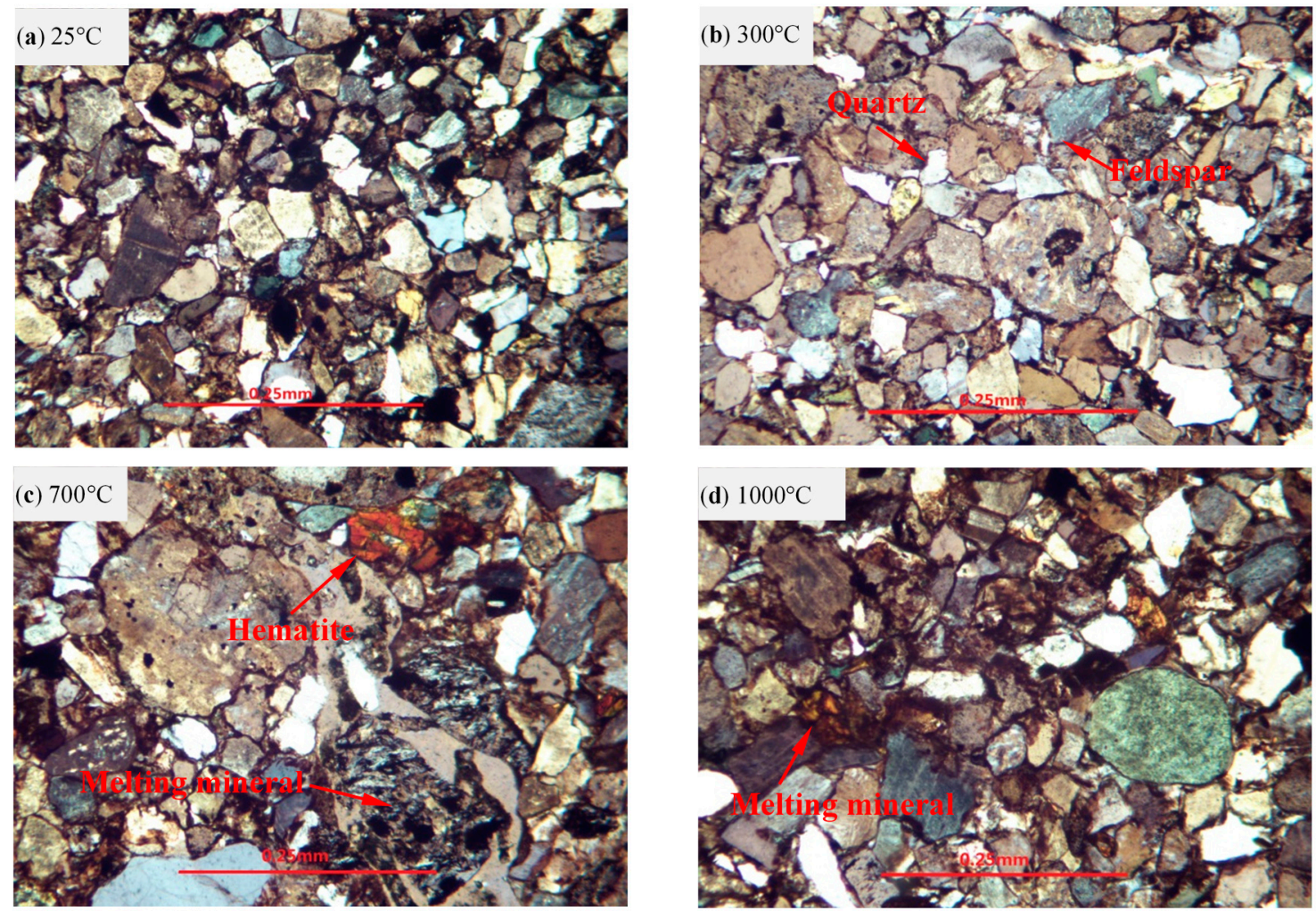

Figure 18. Microscopic structure of red sandstone (polarizing microscopy) used in this research. 


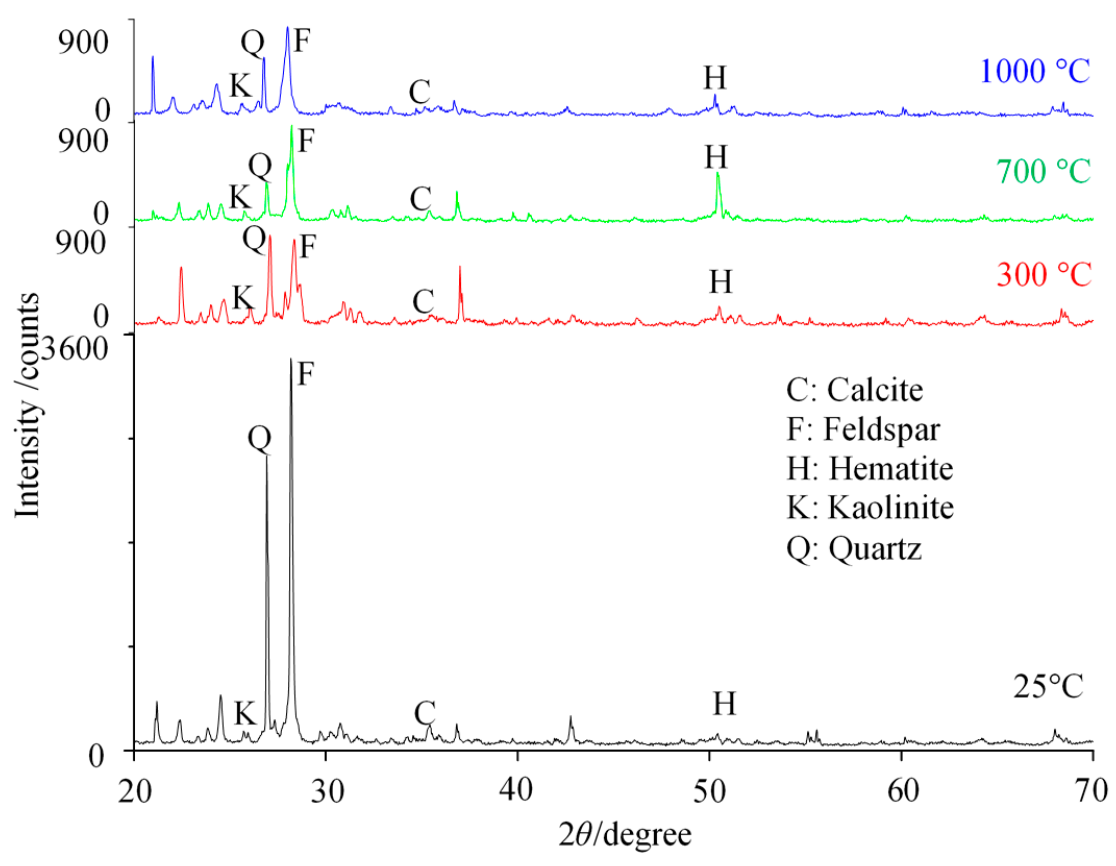

Figure 19. XRD spectra for the powder of sandstone after different thermal treatments.

The main minerals in the tested red sandstone samples were recognized as feldspar, quartz, calcite, hematite and clay minerals. XRD spectra are plotted in Figure 19. The red sandstones showing reddish colors contain mostly a minor amount of ferrous minerals such as hematite. Hajpál and Török [68] reported that the color of sandstones depended on the mineral composition. As quartz is grey and most coloured (brownish-reddish) sandstones contain iron-bearing minerals. Therefore the colour changes in the specimens are related to the transformation of iron-bearing mineral phases at different temperatures. From Figure 19, not distinguishable change can be seen for the quart and feldspar, although the peaks for them decreased sharply as temperature at $300{ }^{\circ} \mathrm{C}$. The kaolinite was becoming less and less with increasing temperature. The calcite disintegrated above $700{ }^{\circ} \mathrm{C}$. Heap et al. [69] reported that the calcite started to decompose as temperature above $680^{\circ} \mathrm{C}$. Hajpál [70] reported that a new mineral phase of hematite appeared and goethite and jarosite disappeared at $900^{\circ} \mathrm{C}$. The hematite was the final reaction product of any iron-bearing oxy-hydroxide at high temperature. Figure 18 illustrates the microscopic structure of specimen after high-temperature treatments by polarizing microscopy. From Figure 18, as temperature increased by $700{ }^{\circ} \mathrm{C}$ and $1000{ }^{\circ} \mathrm{C}$, hematite appeared and some minerals melted, which can explain the color variation of heated specimens.

\section{Conclusions}

The objective of this article was an investigation of the temperature influence on the creep behavior of red sandstone under a high confining pressure $\left(\sigma_{3}=25 \mathrm{MPa}\right)$. Hence, a series of creep experiments was performed. The following conclusions are drawn:

(1) The axial instantaneous strain increased linearly with increasing partial stress at the same temperatures. As the deviatoric stress increased, both the lateral creep strain and the increment in the axial creep strain with time gradually rose, whereas the volumetric creep strain decreased from positive to negative values, which represented the initial compression, dilation, and finally failure by shear dilatancy of the specimens.

(2) Under the same deviatoric stress and as the temperature was increased, the instantaneous deformation modulus $\left(E_{0}\right)$ decreased nonlinearly, the axial creep strain increased gradually, but the lateral creep strain first decreased when the temperature was below $300{ }^{\circ} \mathrm{C}$ and then 
increased when the temperature increased above $300^{\circ} \mathrm{C}$. The bulk expansion became easier as the applied stress approached $\sigma_{\mathrm{p}}$. In addition, as the temperature increased, CSR decreased.

(3) A creep damage model based on strain energy was established, and a secondary development was implemented in $\mathrm{FLAC}^{3 \mathrm{D}}$; the latter can effectively reproduce the entire creep process. In the model, the two damage parameters mainly affect the onset of tertiary creep and its duration.

(4) The axial creep strain had an apparent linear relationship with the lateral creep strain. In addition, the slopes of fit lines increased gradually with increasing deviatoric stress. Under identical deviatoric stresses, the elastic parameters $\left(K, G_{\mathrm{M}}\right.$ and $\left.G_{K}\right)$ and the viscosity coefficient $\left(\eta_{\mathrm{K}}\right)$ of the creep model decreased with temperature, whereas the viscosity coefficient $\left(\eta_{\mathrm{M}}\right)$ at first increased as the temperature rose to $300^{\circ} \mathrm{C}$ and then decreased as temperature exceeded $300{ }^{\circ} \mathrm{C}$.

(5) Nevertheless, despite the preliminary experimental investigation of the thermal influence on the time-dependent behavior and creep damage model of red sandstone, more refined studies are necessary. In particular, further experimental work is essential to provide sufficient tests data to gain a deeper understanding of the mechanism of thermal effects. Furthermore, the coupled thermal and creep damage model requires study, verification and optimization.

Acknowledgments: The research was supported by the Natural Science Foundation of Jiangsu Province for Distinguished Young Scholars (BK20150005), National Natural Science Foundation of China (51734009) and the Fundamental Research Funds for the Central Universities (2015XKZD05). We would also like to acknowledge the editor and two anonymous reviewers for their valuable comments, which have greatly improved this paper.

Author Contributions: Sheng-Qi Yang conceived and designed the experiments; Bo Hu and Peng Xu performed the experiments; Sheng-Qi Yang and Bo Hu analyzed the data; Sheng-Qi Yang and Bo Hu wrote the paper, which was revised by Pathegama G. Ranjith.

Conflicts of Interest: The authors declare that they have no conflicts of interest.

\section{List of Symbols}

$\begin{array}{ll}\text { CSR } & \text { Critical stress ratio } \\ D & \text { Damage variable }(0 \leq D \leq 1) \\ E_{0} & \text { Instantaneous deformation modulus } \\ G_{\mathrm{M}} & \text { Shear modulus of Maxwell body } \\ G_{\mathrm{K}} & \text { Shear modulus of Kelvin body } \\ K & \text { Bulk modulus } \\ P & \text { Differencial stress }\left(P=\sigma_{1}-\sigma_{3}\right) \\ Q & \text { The sum of the least error square } \\ R^{2} & \text { The square of correlation coefficient } \\ S & \text { Deviatoric stress } \\ S_{i j} & \text { Partial stress tensor } \\ S_{\mathrm{e}}, S_{\mathrm{V}}, S_{\mathrm{ve}} & \text { Partial stress tensors on elastic, viscosity and visco-elastic portions } \\ S^{N} & \text { New deviatoric stress for a time step } \\ S^{\circ} & \text { Old deviatoric stress for a time step } \\ \dot{S} & \text { The derivative of } S \\ T & \text { Temperature } \\ t & \text { Creep time } \\ t_{0} & \text { Beginning time of accelerating creep } \\ U^{\mathrm{d}} & \text { Dissipation energy } \\ U_{0}^{d} & \text { Dissipation energy corresponding to the initial damage } \\ U & \text { Strain energy } \\ U_{0} & \text { Critical strain energy } \\ & \end{array}$




\section{Greek Symbols}

\begin{tabular}{|c|c|}
\hline$\sigma_{1}, \sigma_{2}, \sigma_{3}$ & Principle stresses ( $\sigma_{1} \geq \sigma_{3}=\sigma_{2}$ compression positive) \\
\hline$\sigma_{i j}$ & Stress tensor \\
\hline$\sigma_{\mathrm{p}}$ & Triaxial peak strength \\
\hline$\sigma_{\mathrm{cd}}$ & Triaxial damage stress \\
\hline$\sigma_{\mathrm{r}}$ & Triaxial residual strength \\
\hline$\sigma_{\mathrm{c}}$ & Creep failure stress \\
\hline$\sigma_{\mathrm{m}}$ & Spheric stress \\
\hline$\varepsilon_{i j}$ & Strain tensor \\
\hline$\varepsilon_{\mathrm{m}}$ & Spheric strain \\
\hline$\varepsilon_{0}$ & Instantaneous axial strain \\
\hline$\varepsilon_{\mathrm{cr}}$ & Creep strain \\
\hline$e_{i j}$ & Partial strain tensor \\
\hline$e_{\mathrm{e}}, e_{\mathrm{V}}, e_{\mathrm{ve}}$ & Partial strain tensors of elastic, viscosity and visco-elastic portions \\
\hline$\dot{e}_{\mathrm{K}}$ & Partial strain rate of Kelvin body \\
\hline$e_{\mathrm{K}}$ & Partial strain of Kelvin body \\
\hline$e_{\mathrm{M}}$ & Partial strain of Maxwell body \\
\hline$e^{N}$ & New deviatoric strain for a time step \\
\hline$e^{\circ}$ & Old deviatoric strain for a time step \\
\hline$e_{\mathrm{K}}^{N}$ & New deviatoric strain for a time step of Kelvin body \\
\hline$e_{\mathrm{K}}^{O}$ & Old deviatoric strain for a time step of Kelvin body \\
\hline$e_{\mathrm{M}}^{\mathrm{N}}$ & New deviatoric strain for a time step of Maxwell body \\
\hline$e_{\mathrm{M}}^{O}$ & Old deviatoric strain for a time step of Maxwell body \\
\hline$\Delta t$ & Increment step of creep time \\
\hline$\eta_{\mathrm{M}}$ & Viscosity coefficient of Maxwell body \\
\hline$\eta_{\mathrm{K}}$ & Viscosity coefficient of Kelvin body \\
\hline$\mu$ & Poisson's ratio \\
\hline$\alpha$ & Parameter related to the material \\
\hline$\beta$ & Parameter related to the material \\
\hline$\Omega^{0}$ & Initial creep parameter \\
\hline$\Omega^{\mathrm{cd}}$ & Creep parameter rafter creep damage \\
\hline
\end{tabular}

\section{References}

1. Yang, S.Q.; Ranjith, P.G.; Jing, H.W.; Tian, W.L.; Ju, Y. An experimental investigation on thermal damage and failure mechanical behavior of granite after exposure to different high temperature treatments. Geothermics 2017, 65, 180-197. [CrossRef]

2. Yang, S.Q.; Xu, P.; Li, Y.B.; Huang, Y.H. Experimental investigation on triaxial mechanical and permeability behavior of sandstone after exposure to different high temperature treatments. Geothermics 2017, 69, 93-109. [CrossRef]

3. Zhao, Y.S.; Wan, Z.J.; Kang, J.R. Introduction to Geothermal Extraction of Hot Dry Rock; Sciences Press: Beijing, China, 2004; pp. 9-18.

4. Yang, S.Q.; Tian, W.L.; Huang, Y.H. Failure mechanical behavior of pre-holed granite specimens after elevated temperature treatment by particle flow code. Geothermics 2018, 72, 124-137. [CrossRef]

5. Stiegel, G.J.; Ramezan, M. Hydrogen from coal gasification: An economical pathway to a sustainable energy future. Int. J. Coal Geol. 2006, 65, 173-190. [CrossRef]

6. Ranjith, P.G.; Daniel, R.V.; Chen, B.J.; Perera, M.S.A. Transformation plasticity and the effect of temperature on the mechanical behaviour of Hawkesbury sandstone at atmospheric pressure. Eng. Geol. 2012, 151, 120-127.

7. Yang, S.Q.; Tian, W.L.; Ranjith, P.G. Experimental investigation on deformation failure characteristics of crystalline marble under triaxial cyclic loading. Rock. Mech. Rock Eng. 2017, 50, 2871-2889. [CrossRef]

8. Voight, B. Structural stability of andesite volcanoes and lava domes. Philos. Trans. R. Soc. A 2000, 358, 1663-1703. [CrossRef] 
9. Watters, R.J.; Zimbelman, D.R.; Bowman, S.D.; Crowley, J.K. Rock mass strength assessment and significant to edifice stability, Mt Rainer and Mt Hood, Cascade Range volcanoes. Pure Appl. Geophys. 2005, 157, 957-976. [CrossRef]

10. Heap, M.J.; Baud, P.; Meredith, P.G. The influence of temperature on brittle creep in sandstones. Geophys. Res. Lett. 2009, 36, L19305. [CrossRef]

11. Heap, M.J.; Baud, P.; Meredith, P.G.; Vinciguerra, S.; Bell, A.F.; Main, I.G. Brittle creep in basalt and its application to time-dependent volcano deformation. Earth Planet Sci. Lett. 2011, 307, 71-82. [CrossRef]

12. Logan, S.E. Deep self-burial of radioactive wastes by rock-melting capsules. Nucl. Technol. 1974, 21, 111-124. [CrossRef]

13. Heuze, F.E. On the Geotechnical Modelling of High-Level Nuclear Waste Disposal by Rock Melting; UCRL-53183; Lawrence Livermore Laboratory: Livermore, CA, USA, 1981.

14. Gibb, S.E. High-temperature, very deep geological disposal: A safer alternative for high-level radioactive waste? Waste Manag. 1999, 19, 207-211. [CrossRef]

15. Qin, B.D.; Chen, L.J.; Liu, X. Experimental research on the swelling stresses in limestone at high temperatures. J. China Univ. Min. Technol. 2009, 38, 326-330.

16. Michalski, S.R. The jharia mine fire control technical assistance project: An analysis. Int. J. Coal Geol. 2004, 59, 83-90. [CrossRef]

17. Otto, C.; Kempka, T. Thermo-mechanical simulations of rock behavior in underground coal gasification show negligible impact of temperature dependent parameters on permeability changes. Energies 2015, 8, 5800-5827. [CrossRef]

18. Goetze, C.; Brace, W.F. Laboratory observations of high-temperature rheology of rocks. Tectonophysics 1972, 13, 583-600. [CrossRef]

19. Weertman, J.; Weertman, J.R. High temperature creep of rock and mantle viscosity. Annu. Rev. Earth Planet Sci. 1975, 3, 293-315. [CrossRef]

20. Post, R.L. High temperature creep of Mt. Burnet dunite. Tectonophysics 1977, 42, 75-110. [CrossRef]

21. Zhou, Y.S.; He, C.R.; Huang, X.G.; Song, J.; Sang, Z. Rheological complexity of mafic rocks and effect of mineral component on creep of rocks. Earth Sci. Front. 2009, 16, 76-87.

22. Chen, L.; Wang, C.P.; Liu, J.F.; Li, Y.; Liu, J.; Wang, J. Effects of temperature and stress on the time-dependent behavior of Beishan granite. Int. J. Rock Mech. Min. Sci. 2017, 93, 16-323. [CrossRef]

23. Lipponen, A.; Manninen, S.; Niini, H.; Ro, E. Effect of water and geological factors on the long-term stability of fracture zones in the Päijänne Tunnel, Finland: A case study. Int. J. Rock Mech. Min. Sci. 2005, 42, 3-12. [CrossRef]

24. Cao, P.; Wan, L.H.; Wang, Y.X.; Huang, Y.H.; Zhang, X.Y. Viscoelasto-plastic properties of deep hard rocks under water environment. Trans. Nonferrous Met. Soc. China 2011, 21, 2711-2718. [CrossRef]

25. Yang, S.Q.; Jing, H.W.; Cheng, L. Influences of pore pressure on short-term and creep mechanical behavior of red sandstone. Eng. Geol. 2014, 179, 10-23. [CrossRef]

26. Tsai, L.S.; Hsieh, Y.M.; Weng, M.C.; Huang, T.H.; Jeng, F.S. Time-dependent deformation behaviors of weak sandstones. Int. J. Rock Mech. Min. Sci. 2008, 45, 144-154. [CrossRef]

27. Heap, M.J.; Baud, P.; Meredith, P.G.; Bell, A.F.; Main, I.G. Time-dependent brittle creep in Darley Dale sandstone. J. Geophys. Res. 2009, 114, 4288-4309. [CrossRef]

28. Yang, D.S.; Chen, L.F.; Yang, S.Q. Experimental investigation of the creep and damage behavior of Linyi red sandstone. Int. J. Rock Mech. Min. Sci. 2014, 72, 164-172. [CrossRef]

29. Maranini, E.; Brignoli, M. Creep behaviour of a weak rock: Experimental characterization. Int. J. Rock Mech. Min. Sci. 1999, 36, 127-138. [CrossRef]

30. Brantut, N.; Heap, M.J.; Meredith, P.G.; Baud, P. Time-dependent cracking and brittle creep in crustal rocks: A review. J. Struct. Geol. 2013, 52, 17-43. [CrossRef]

31. Cristescu, N. Rock Rheology; Kluwer Academic: Dordrecht, The Netherlands, 1989.

32. Chopra, P.N. High-temperature transient creep in olivine rocks. Tectonophysics 1997, 279, 93-111. [CrossRef]

33. Ferrero, A.M.; Marini, P. Technical note experimental studies on the mechanical behavior of two thermal cracked marbles. Rock Mech. Rock Eng. 2001, 34, 57-66. [CrossRef]

34. Du, S.J.; Liu, H.; Zhi, H.T.; Chen, H.H. Testing study on mechanical properties of post-high-temperature granite. Chin. J. Rock Mech. Eng. 2004, 23, 2359-2364. (In Chinese) 
35. Brotóns, V.; Tomás, R.; Ivorra, S.; Alarcón, J.C. Temperature influence on the physical and mechanical properties of a porous rock: San Julian' calcarenite. Eng. Geol. 2013, 167, 117-127. [CrossRef]

36. Tian, H.; Kempka, T.; Xu, N.X.; Ziegler, M. Physical properties of sandstones after high temperature. Rock Mech. Rock. Eng. 2012, 45, 1113-1117. [CrossRef]

37. Tian, H.; Kempka, T.; Yu, S.; Ziegler, M. Mechanical properties of sandstones exposed to high temperature. Rock Mech. Rock. Eng. 2016, 49, 321-327. [CrossRef]

38. Tian, H.; Ziegler, M.; Kempka, T. Physical and mechanical behavior of claystone exposed to temperature up to $1000{ }^{\circ}$ C. Int. J. Rock Mech. Min. Sci. 2014, 70, 144-153. [CrossRef]

39. Li, M.; Mao, X.B.; Cao, L.L.; Mao, R.R.; Tao, J. Experimental study of mechanical properties on strain rate effect of sandstones after high temperature. Chin. Rock Soil. Mech. 2014, 23, 3479-3488.

40. Ye, G.L.; Nishimura, T.; Zhang, F. Experimental study on shear and creep behaviour of green tuff at high temperatures. Int. J. Rock Mech. Min. Sci. 2015, 79, 19-28. [CrossRef]

41. Sun, Q.; Lü, C.; Cao, L.W.; Li, W.C.; Geng, J.S.; Zhang, W.Q. Thermal properties of sandstone after treatment at high temperature. Int. J. Rock Mech. Min. Sci. 2016, 85, 60-66. [CrossRef]

42. Carter, N.L.; Horseman, S.T.; Russell, J.E.; Handin, J. Rheology of rock-salt. J. Struct. Geol. 1993, 15, $1257-1271$. [CrossRef]

43. Main, I.G. A damage mechanics model for power-law creep and earthquake aftershock and foreshock sequences. Geophys. J. Int. 2000, 142, 151-161. [CrossRef]

44. Burgers, J.M. Mechanical Considerations-Model Systems-Phenomenological Theories of Relaxation and of Viscosity; Nordemann Publishing Company: New York, NY, USA, 1935.

45. Fahimifar, A.; Tehrani, F.M.; Hedayat, A.; Vakilazdeh, A. Analytical solution for the excavation of circular tunnels in a visco-elastic Burger's material under hydrostatic stress field. Tunn. Undergr. Space Technol. 2010, 25, 297-304. [CrossRef]

46. Zhao, Y.L.; Wang, Y.X.; Wang, W.J.; Tang, J.Z. Modeling of non-linear rheological behavior of hard rock using triaxial rheological experiment. Int. J. Rock Mech. Min. Sci. 2017, 93, 66-75. [CrossRef]

47. Valanis, K.C. Theory of viscoplasticity without a yield surface Part.1. Gen. Theory Arch. Mech. 1971, $23,517$.

48. Yang, C.H.; Wang, W.L.; Fan, J.H. A kind of endochronic constitutive description of mechanical properties of soft rock under static loading. Rock Soil Mech. 1987, 8, 11-17. (In Chinese)

49. Abu Al-Rub, R.K.; Darabi, M.K. A thermodynamic framework for constitutive modeling of time- and rate-dependent materials. Part I: Theory. Int. J. Plast. 2012, 34, 61-92. [CrossRef]

50. Xie, H.P.; Peng, R.D.; Ju, Y. Energy dissipation of rock deformation and fracture. Chin. J. Rock Mech. Eng. 2004, 23, 3565-3570. (In Chinese)

51. Yoshida, H.; Horii, H. A micromechanics-based model for creep behavior of rock. Appl. Mech. Rev. 1992, 45, 294-303. [CrossRef]

52. Lu, Y.L.; Elswort, D.; Wang, L.G. A dual-scale approach to model time-dependent deformation, creep and fracturing of brittle rocks. Comput. Geotech. 2014, 60, 61-76. [CrossRef]

53. Shao, J.F.; Chau, K.T.; Feng, X.T. Modeling of anisotropic damage and creep deformation in brittle rocks. Int. J. Rock Mech. Min. Sci. 2006, 43, 582-592. [CrossRef]

54. Kachanov, L.M. Time of the rupture process under creep conditions. Izv. Akad. Nauk S S R Otd. Tech. Nauk 1958, 8, 26-31.

55. Lemaitre, J. Evaluation of dissipation and damage in metals under dynamic loading. In Proceedings of the International Congress on Mechanical Behavior of Materials (ICM), Kyoto, Japan, August 1971.

56. Murakami, S. Notion of Continuum Damage Mechanics and Its Application to Anisotropic Creep Damage Theory. J. Eng. Mater. Technol. 1983, 105, 99-105. [CrossRef]

57. Kyoya, T. A damage mechanics theory for discontinuous rock mass. In Proceedings of the Fifth International Conference on Numerical Methods in Geomechanics, Nagoya, Japan, 1-5 April 1985; pp. 469-480.

58. Lockner, D.; Byerlee, J. Acoustic emission and creep in rocks at high confining pressure and differential stress. Bull. Seismol. Soc. Am. 1977, 67, 247-258.

59. Baud, P.; Meredith, P.G. Damage accumulation during triaxial creep of Darley Dale sandstone from pore volumometry and acoustic emission. Int. J. Rock Mech. Min. Sci. 1997, 34, 24.e1-24.e10. [CrossRef]

60. Atkinson, B.K. Subcritical crack growth in geological materials. J. Geophys. Res. 1984, 89, 4077-4114. [CrossRef] 
61. Meredith, P.G.; Atkinson, B.K. Stress corrosion and acoustic emission during tensile crack propagation in Whin Sill dolerite and other basic rocks. Geophys. J. Int. 1983, 75, 1-21. [CrossRef]

62. Yang, S.Q.; Xu, P.; Ranjith, P.G. Damage model of coal under creep and triaxial compression. Int. J. Rock Mech. Min. Sci. 2015, 80, 337-345. [CrossRef]

63. Xie, H.P.; Li, L.; Peng, R.; Ju, Y. Energy analysis and criteria for structural failure of rocks. J. Rock Mech. Geotech. Eng. 2009, 1, 11-20. [CrossRef]

64. Lin, Q.X.; Liu, Y.M.; Tham, L.G.; Tang, C.A.; Lee, P.K.K.; Wang, J. Time-dependent strength degradation of granite. Int. J. Rock Mech. Min. Sci. 2009, 46, 1103-1114. [CrossRef]

65. Yu, T.Q.; Wang, X.W.; Liu, Z.H. Elasticity and Plasticity; China Architecture and Building Press: Beijing, China, 2004.

66. Sun, J. Rheological Behavior of Geomaterials and Its Engineering Applications; China Architecture and Building Press: Beijing, China, 1999.

67. Wong, T.F. Effects of temperature and pressure on failure and post-failure behavior of Westerly granite. Mech. Mater. 1982, 1, 3-17. [CrossRef]

68. Hajpál, M.; Török, Á. Mineralogical and colour changes of quartz sandstones by heat. Environ. Geol. 2004, 46, 311-322. [CrossRef]

69. Heap, M.J.; Mollo, S.; Vinciguerra, S. Thermal weakening of the carbonate basement under Mt. Etna volcano (Italy): Implications for volcano instability. J. Volcanol. Geotherm. Res. 2013, 250, 42-60. [CrossRef]

70. Hajpál, M. Changes in Sandstones due to Thermal Effect. Unpublished Ph.D. Thesis, Budapest University of Technology and Economics, Budapest, Hungary, 2002. (In Hungarian with English and German Abstract).

(C) 2018 by the authors. Licensee MDPI, Basel, Switzerland. This article is an open access article distributed under the terms and conditions of the Creative Commons Attribution (CC BY) license (http:/ / creativecommons.org/licenses/by/4.0/). 